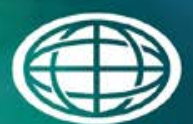

Savannah River

National Laboratory ${ }^{m}$

OPERATED BY SAVANNAH RIVER NUCLEAR SOLUTIONS

\title{
SHINE Vacuum Pump Test Verification
}

Gregg A. Morgan and Brent Peters

September 2013

SRNL-STI-2013-00539 
SRNL-STI-2013-00539

Revision 0

\section{DISCLAIMER}

This work was prepared under an agreement with and funded by the U.S. Government. Neither the U.S. Government or its employees, nor any of its contractors, subcontractors or their employees, makes any express or implied:

1. warranty or assumes any legal liability for the accuracy, completeness, or for the use or results of such use of any information, product, or process disclosed; or

2. representation that such use or results of such use would not infringe privately owned rights; or

3. endorsement or recommendation of any specifically identified commercial product, process, or service.

Any views and opinions of authors expressed in this work do not necessarily state or reflect those of the United States Government, or its contractors, or subcontractors.

\section{Printed in the United States of America \\ Prepared for \\ U.S. Department of Energy}


Keywords: Tritium processing system, tritium purification, SHINE, vacuum pumps,

Track \#: 10560

Retention: Permanent

\title{
SHINE Vacuum Pump Test Verification
}

\author{
G.A. Morgan \\ B. Peters
}

September 2013

Prepared for the U.S. Department of Energy under contract number DE-AC09-08SR22470.

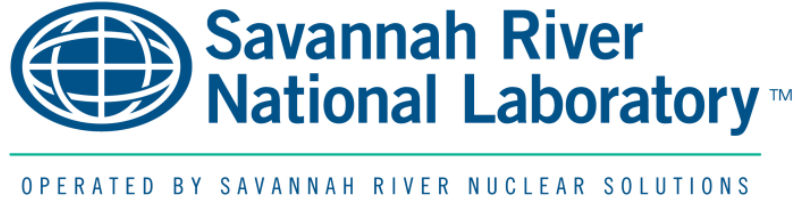




\section{ACKNOWLEDGEMENTS}

The authors gratefully acknowledge Anita Poore, Joseph Wheeler, Henry Sessions, and Michael Aldinger for their support of this work. 


\section{EXECUTIVE SUMMARY}

Normetex pumps used world-wide for tritium service are no longer available. DOE and other researchers worldwide have spent significant funds characterizing this pump. Identification of alternate pumps is required for performance and compatibility with tritium gas. Many of the pumps that could be used to meet the functional performance requirements (e.g. pressure and flow conditions) of the Normetex pump have features that include the use of polymers or oils and greases that are not directly compatible with tritium service. This study assembles a test system to determine the flow characteristics for candidate alternate pumps. These tests are critical to the movement of tritium through the SHINE Tritium Purification System (TPS).

The purpose of the pump testing is two-fold: (1) obtain baseline vacuum pump characteristics for an alternate (i.e. "Normetex replacement") pump intended for use in tritium service; and (2) verify that low pressure hydrogen gas can be transported over distances up to 300 feet by the candidate pumps. Flow rates and nominal system pressures have been identified for the SHINE Mo-99 production process Tritium Purification System (TPS). To minimize the line sizes for the transfer of low pressure tritium from the Neutron Driver Accelerator System (NDAS) to the primary processing systems in the TPS, a "booster" pump has been located near the accelerator in the design. A series of pump tests were performed at various configurations using hydrogen gas (no tritium) to ensure that this concept is practical and maintains adequate flow rates and required pressures. This report summarizes the results of the tests that have been performed using various pump configurations.

The current design of the Tritium Purification System requires the "booster" pump to discharge to or to be backed by another vacuum pump. Since Normetex pumps are no longer manufactured, a commercially available Edwards scroll pump will be used to back the booster pump. In this case the "booster pump" is an Adixen Molecular Drag Pump (MDP 5011) and the backing pump is an Edwards (nXDS15iC) scroll pump. Various configurations of the two pumps and associated lengths of $3 / 4$ inch tubing ( 0 feet to 300 feet) were used in combination with hydrogen and nitrogen flow rates ranging from 25-400 standard cubic centimeters per minute (sccm) to determine whether the proposed pump configuration meets the design criteria for SHINE.

The results of this study indicate that even under the most severe conditions (300 feet of tubing and 400 sccm flow rate) the Adixen 5011 MDP can serve as a booster pump to transport gases from the accelerator (NDAS) to the TPS. The Target Gas Receiving System pump (Edwards nXDS15iC) located approximately 300 feet from the accelerator can effectively back the Adixen MDP. The molecular drag pump was able to maintain its full rotational speed even when the flow rate was $400 \mathrm{sccm}$ hydrogen or nitrogen and 300 feet of tubing was installed between the drag pump and the Edwards scroll pump. In addition to maintaining adequate rotation, the pressure in the system was maintained below the target pressure of 30 torr for all flow rates, lengths of tubing, and process gases. This configuration is therefore adequate to meet the SHINE design requirements in terms of flow and pressure. 


\section{TABLE OF CONTENTS}

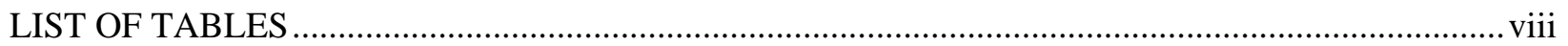

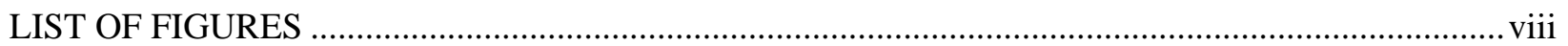

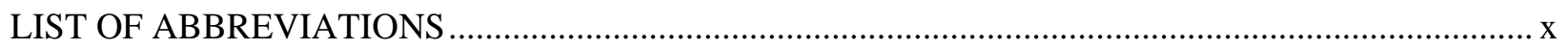

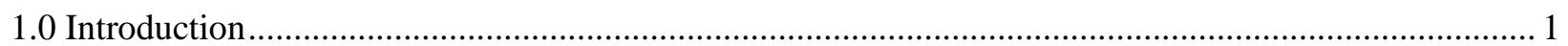

1.1 Pump Identification for the Tritium Purification System............................................................... 1

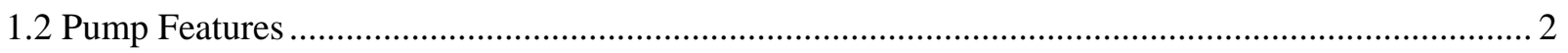

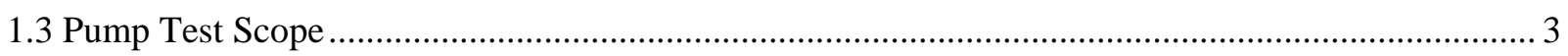

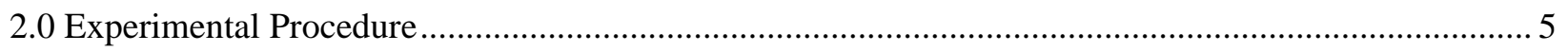

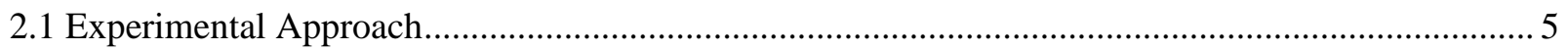

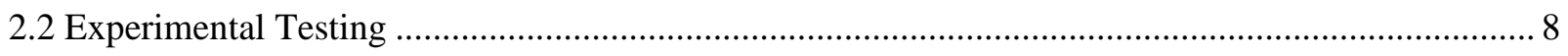

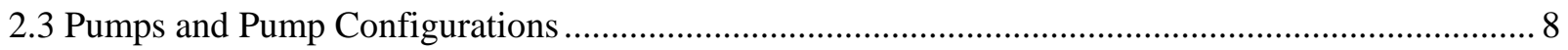

2.4 Edwards nXDS15iC Pump Pressure Rating and Compression Testing ........................................... 9

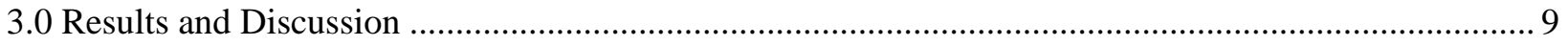

3.1 Pressure/Compression Test Results....................................................................................... 9

3.1.1 Pumping Using the MB-601 Pump to Vary Discharge Pressure (with inlet blocked)................ 10

3.1.2 Pumping with a Blocked Inlet and Discharge Side of the Pump .............................................. 11

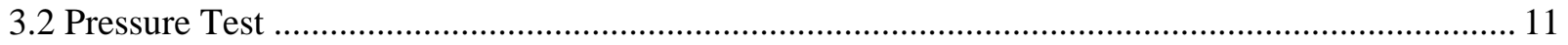

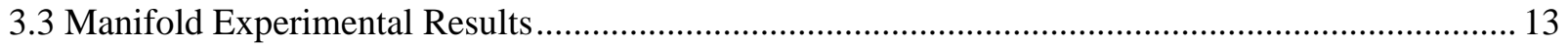

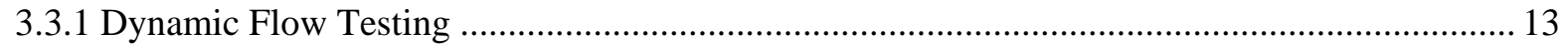

3.3.2 Static Pump Down Testing ..................................................................................................... 27

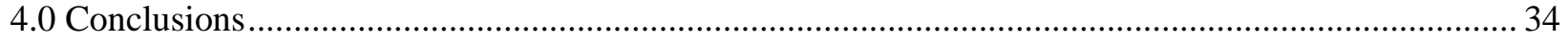

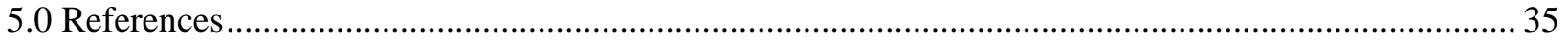




\section{LIST OF TABLES}

Table 3-1: Edwards pump suction blanked off using metal bellows backing pump................................ 10

Table 3-2: Edwards Pump Inlet and Discharge Ports Blanked Off....................................................... 11

\section{LIST OF FIGURES}

Figure 1-1: Interface Schematic for the Accelerator and the Tritium Purification System ........................ 2

Figure 1-2: Potential Pump Configurations for the SHINE Tritium Purification System .......................... 2

Figure 1-3: TGRS pump train configuration for SHINE TPS. .............................................................. 3

Figure 2-1: SHINE Vacuum Pump Test Manifold Schematic ............................................................... 6

Figure 2-2: SHINE Vacuum Pump Test Manifold .............................................................................. 7

Figure 3-1: Edwards nXDS15iC Pump Test Setup Schematic with inlet blanked off............................. 10

Figure 3-2: Edwards nXDS15iC Pump Test Setup Schematic with Inlet and Discharge Blocked............ 11

Figure 3-3: Edwards nXDS15iC Scroll Pump in 723-A Walk-in Gun Barrel ......................................... 12

Figure 3-4: Edwards nXDS15iC Scroll Pump after Pressure/Burst Testing............................................ 12

Figure 3-5: Pressure vs. Time plot for hydrogen with the Edwards pump and 0 feet of tubing................ 13

Figure 3-6: Pressure vs. Time plot for hydrogen with the Edwards pump and the Adixen molecular drag

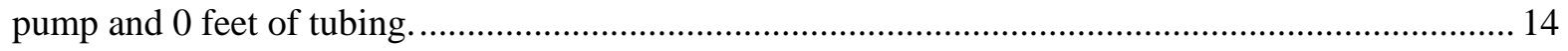

Figure 3-7: Pressure vs. Time plot for hydrogen with the Edwards pump and 300 feet of tubing. ........... 15

Figure 3-8: Pressure vs. Time plot for nitrogen with the Edwards pump and 0 feet of tubing.................. 16

Figure 3-9: Pressure vs. Time plot for nitrogen with the Edwards pump and 300 feet of tubing.............. 17

Figure 3-10: Pressure vs. Time plot for hydrogen with the Edwards pump and 0 feet of tubing.............. 18

Figure 3-11: Pressure vs. Time plot for hydrogen with the Edwards pump and 300 feet of tubing. ......... 19

Figure 3-12: Pressure vs. Time plot of hydrogen with the Edwards pump and 250 feet of tubing. .......... 20

Figure 3-13: Pressure vs. Time plot for nitrogen with the Edwards pump, Adixen molecular drag pump,

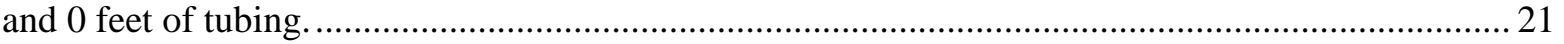

Figure 3-14: Pressure vs. Time plot for nitrogen with the Edwards pump, Adixen molecular drag pump,

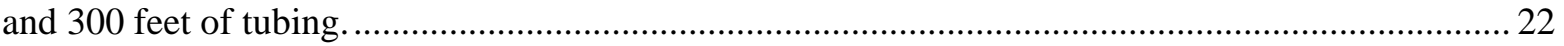

Figure 3-15: Pressure vs. Time plot for hydrogen with the Edwards pump, Adixen molecular drag pump,

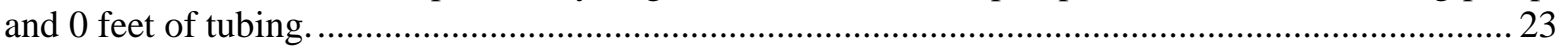


Figure 3-16: Pressure vs. Time plot for hydrogen with the Edwards pump, Adixen molecular drag pump, and 300 feet of tubing.

Figure 3-17: Temperature vs. Time plot for nitrogen with the Edwards pump, Adixen molecular drag pump, and 0 feet of tubing.

Figure 3-18: Temperature vs. Time plot for plot hydrogen with the Edwards pump, Adixen molecular

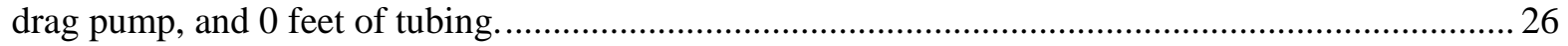

Figure 3-19: Pressure vs. Time plot for tank pump down test with hydrogen with the Edwards pump and 0 feet of tubing. 27

Figure 3-20: Pressure vs. Time plot for tank pump down test with nitrogen with the Edwards pump and 0

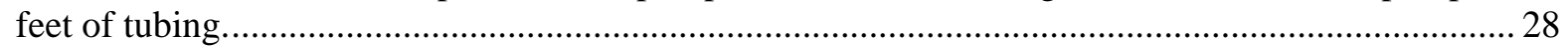

Figure 3-21: Pressure vs. Time plot for tank pump down test with hydrogen with the Edwards pump and 300 feet of tubing...... 29

Figure 3-22: Pressure vs. Time plot for tank pump down test with nitrogen with the Edwards pump and 300 feet of tubing. 30

Figure 3-23: Pressure vs. Time plot for the various test conditions at PT02 .......................................... 31

Figure 3-24: Pressure vs. Time plot for the various test conditions at PT03 …...................................... 32

Figure 3-25: Pressure vs. Time plot for the various test conditions at PT04 ......................................... 33 


\section{LIST OF ABBREVIATIONS}

\begin{tabular}{|c|c|c|c|c|}
\hline ATIS & Accelerator Tritium Interface System & & & \\
\hline MB & Metal Bellows & & & \\
\hline MDP & Molecular Drag Pump & & & \\
\hline MFC & Mass Flow Controller & & & \\
\hline NDAS & Neutron Driver Accelerator System & & & \\
\hline PESS & Process Evacuation Stripper System & & & \\
\hline PFD & Process Flow Diagrams & & & \\
\hline $\mathrm{PT}$ & Pressure Transducer & & & \\
\hline Reg & Pressure Regulator & & & \\
\hline $\mathrm{RPM}$ & Rotations per Minute & & & \\
\hline $\mathrm{RV}$ & Relief Valve & & & \\
\hline $\mathrm{sccm}$ & Standard Cubic Centimeters per Minute & & & \\
\hline SHINE & $\begin{array}{l}\text { Subcritical Hybrid Intense Neutron } \\
\text { Technologies }^{\mathrm{TM}}\end{array}$ & Emitter, & SHINE & Medical \\
\hline SRNL & Savannah River National Laboratory & & & \\
\hline SRS & Savannah River Site & & & \\
\hline TC & Thermocouple & & & \\
\hline TGRS & Target Gas Receiving System & & & \\
\hline TMP & Turbomolecular Pump & & & \\
\hline TPS & Tritium Purification System & & & \\
\hline TPS-EVAC & TPS Evacuation System & & & \\
\hline
\end{tabular}




\subsection{Introduction}

Normetex pumps used world-wide for tritium service are no longer available. DOE and researchers worldwide have spent significant funds characterizing this pump. A Normetex ${ }^{\circledR}$ Model 15 scroll pump backed by metal bellows (MB) pump made by Senior Flexonics Inc. has been the preferred technology for use in tritium facilities worldwide. Utilizing this technology has allowed systems containing tritium to be pumped down to pressures as low as $\sim 10^{-3}$ torr. The key design feature of the Normetex ${ }^{\circledR}$ pumps was that their all-metal construction did not introduce contaminates into the tritium process and while the MB pumps had polymer-based check valves, they had a minimal impact on impurity introduction. In 2012, the company that manufactured the Normetex ${ }^{\circledR}$ pump ceased operations. Since that time, SRS Tritium Facilities has been working with several vendors to develop a replacement pump for the Normetex ${ }^{\circledR}$ Model 15 scroll pump; however, while some advances have been made, the effort to develop a full replacement is still in progress. Identification of alternate pumps is required for performance and compatibility with tritium gas. Many of the pumps that could be used to meet the functional performance requirements (e.g. pressure and flow conditions) of the Normetex pump have features that include the use of polymers or oils and greases that are not directly compatible with tritium service.

The purpose of the pump testing is two-fold: (1) obtain baseline vacuum pump characteristics for an alternate (i.e. "Normetex replacement") pump intended for use in tritium service; and (2) verify that low pressure hydrogen gas can be transported over distances up to 300 feet by the candidate pumps. Flow rates and nominal system pressures have been identified for the SHINE Mo-99 production process Tritium Purification System (TPS). To minimize the line sizes for the transfer of low pressure tritium from the Neutron Driver Accelerator System (NDAS) to the primary processing systems in the TPS, a "booster" pump has been located near the accelerator. A series of pump tests were performed at various configurations using hydrogen gas (no tritium) to ensure that this concept is practical and maintains adequate flow rates and required pressures.

This study assembles a test system to determine the flow characteristics for candidate alternate pumps. These tests are critical to the movement of tritium gases through the SHINE Tritium Purification System (TPS). This report summarizes the results of the tests that have been performed using various pump configurations.

\subsection{Pump Identification for the Tritium Purification System}

The Target Gas Receiving System (TGRS) receives the effluent tritium-containing gaseous stream from the Neutron Driver Accelerator System (NDAS) via the Accelerator Tritium Interface System (ATIS) during the production of neutrons, as shown in the interface block diagram given in Figure 1-1. Process flow diagrams (PFDs) from the TPS Pre-Conceptual Design (1) show a pumping configuration that incorporates a turbomolecular pump backed by a Normetex ${ }^{\circledR} / \mathrm{MB}$ pump combination to collect this gaseous stream. The distance between the TPS glovebox room and the accelerator was estimated to be approximately 300 feet. The preconceptual design of the TPS describes flow rates and pressures within those 300 feet as 25-400 standard cubic centimeters per minute (sccm) and 0-40 torr, respectively. Standard conditions are taken as 760 torr and $0^{\circ} \mathrm{C}$. The 40 torr value stated was actually a maximum continuous discharge pressure of 40 mbar for a candidate test pump and is equal to 30 torr. Based on SRS experience and ITER (International Tokamak Fusion Reactor in Cadarache, France) system designs, large internal diameter vacuum lines would be required between the ATIS and the TPS glovebox to continuously recover the tritium for processing if a turbomolecular pump was used in the TGRS. The TPS Technology Identification and Development Report (2) suggested the plan for the 
evaluation of a "booster" pump (Adixen 5011 MDP), which would be located near the NDAS to increase the pressure of the effluent tritium stream, eliminating the need for a TGRS turbomolecular pump.

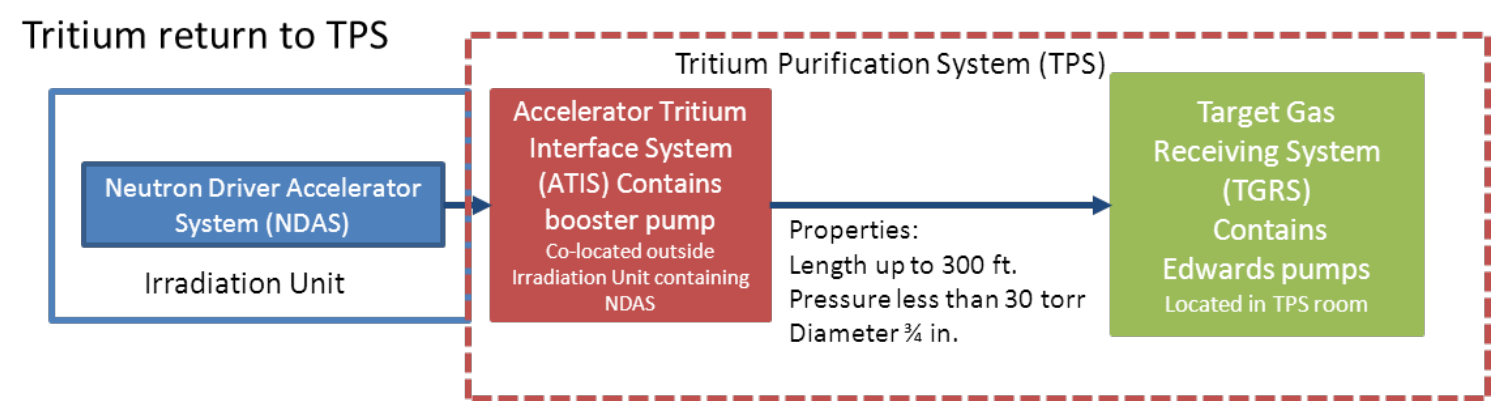

Figure 1-1: Interface Schematic for the Accelerator and the Tritium Purification System

Additionally, Normetex ${ }^{\circledR} / \mathrm{MB}$ pumping combinations were shown in the PFDs in the SHINE TPS Pre-Conceptual Design Report (1); however, the need for the identification of alternative pumping systems was documented in the TPS Technology Identification and Development Report. (2) Potential pump configurations were further described in the TPS Technology Assessment Report (3), and are listed in Figure 1-2.

\begin{tabular}{|l|c|c|c|c|}
\hline Potential Pump Configurations & \begin{tabular}{l} 
Conceptual Design \\
\hline Pumps
\end{tabular} & $\begin{array}{l}\text { Pre-Conceptual } \\
\text { Design }\end{array}$ & \multicolumn{3}{|c|}{} \\
\cline { 3 - 5 } & Startup & Partial Retrofit & Full Retrofit \\
\hline ATS Booster & N/A & Adixen 5011 MDP & Adixen 5011 MDP & Adixen 5011 MDP \\
\hline TMP & Normetex & Edwards nXDS15i & Edwards nXDS15i & $\begin{array}{c}\text { Normetex (or } \\
\text { replacement) }\end{array}$ \\
\hline TGRS & MB-601 & N/A & TBD/MB-601 & TBD/MB-601 \\
\hline Backing & & & & \\
\hline
\end{tabular}

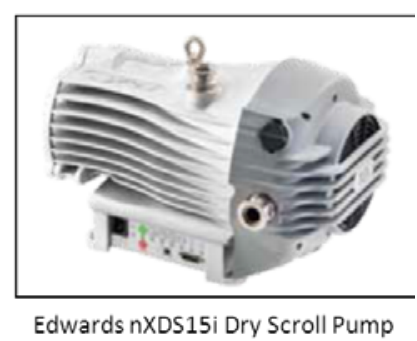

Figure 1-2: Potential Pump Configurations for the SHINE Tritium Purification System

Figure 1-3 shows the current TGRS pump train configuration that will be used to receive gas from the ATIS as given in the TPS Process Flow Diagram. (4) This configuration was used during the design of the SHINE vacuum pump test.

\subsection{Pump Features}

The commercially-available Edwards nXDS15iC pump is a corrosion resistant model, but contains a polytetrafluoroethylene (PTFE, Teflon) tip seal. In addition, the corrosion resistant model also contains Chemraz ${ }^{\circledR}$ internal valves, a perfluoroelastomer (FFKM) in the O-ring, and stainless steel fittings for extra protection from the pumped media. The Edwards pump is lubricant free within the vacuum envelope and hermetically sealed resulting in a totally clean and dry vacuum preventing cross-contamination. This pump also features bearings that are completely isolated because of a lack of an atmosphere to vacuum shaft seal.

The Adixen 5011 MDP (booster pump) contains various non-metallic (non-stainless steel) components that can potentially react with tritium. The Adixen 5011 MDP contains Viton O- 
rings, an epoxy compound on the shaft, and a perfluoroelastomer bearing grease that all have the potential to interact with the process gas.

The issues associated with polymer components in tritium service for the Normetex pump replacement are further described in the "Normetex Pump Alternatives Study" report. (5) The use of pumps containing polymers in high concentration tritium service requires additional design and maintenance considerations. The service life of the Edwards (or Adixen) pump in a nearly pure tritium process stream is speculated to be only 3-6 months due to its polymer seals whereas the all-metal Normetex pump can last for up to 5 years. Layout considerations for maintenance and replacement or the installation of redundant pumps are required for long term service in this high tritium concentration environment. Additionally, particulate filters should be installed to minimize the potential for degraded elastomer particles that are shed by the pump operation from entering the process system piping.

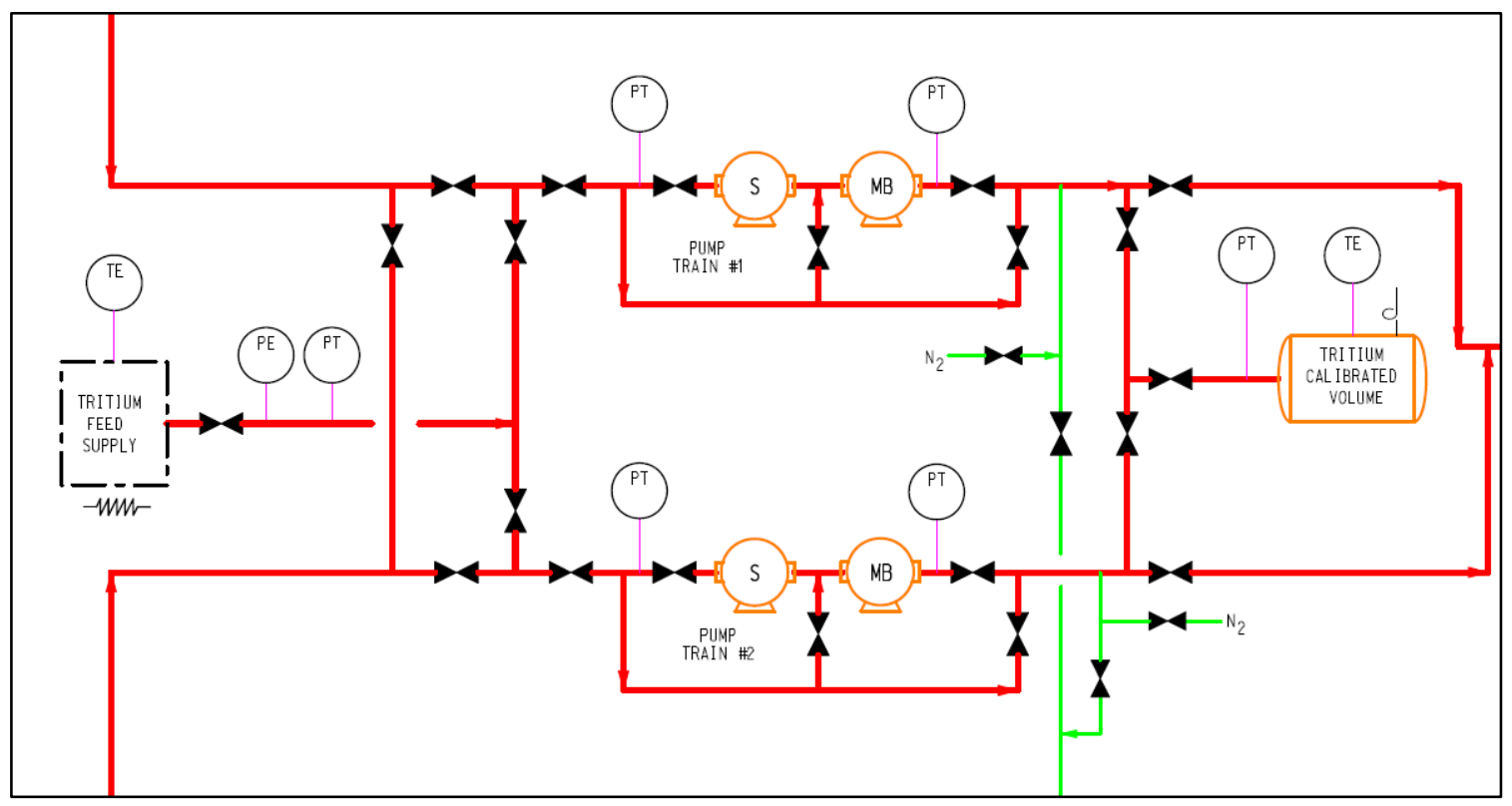

Figure 1-3: TGRS pump train configuration for SHINE TPS.

\subsection{Pump Test Scope}

The scope of the pump testing includes two objectives: obtain baseline vacuum pump characteristics for an alternate (i.e. "Normetex replacement") pump intended for use in tritium service; and (2) verify that low pressure hydrogen gas can be transported over distances up to 300 feet by the candidate pumps. The vacuum pump study is focused on the evaluation of a "booster" pump for the gaseous tritium stream from the NDAS to the TPS TGRS. However, because the Normetex ${ }^{\circledR} / \mathrm{MB}$ pump combinations are not available, alternative pumps will be used within the TGRS to receive the gas from the "booster" pump.

The vacuum pump study includes the following elements:

1. Pressure protection verification testing

2. Flow rate vs. pressure characterization for Edwards pump at various piping length 
3. Flow rate vs. pressure characterization for Adixen and Edwards pump system at various piping lengths

4. Pump down tests of a nominal 45-L volume using the Edwards pump with hydrogen and nitrogen. 
SRNL-STI-2013-00539

Revision 0

\subsection{Experimental Procedure}

\subsection{Experimental Approach}

A pump test system was designed and built to accommodate the pump verification studies. The system was built of primarily $1 / 2$ " stainless steel VCR fittings and SS-8BW-V47 Swagelok valves. A schematic of the system is shown in Figure 2-1 and a photograph is shown in Figure 2-2. The design of the system allows both nitrogen and hydrogen from compressed gas cylinders to be supplied independently, to the system through mass flow controllers (MFCs) at the desired flow rates. Soft copper tubing (3/4" diameter, 0.035" wall), was connected in 50 foot increments to determine the impact of line length on system pumping performance.

In addition a nominal 45-L volume was connected to the system that was used to determine the pump down performance of the Edwards scroll pump. The system contains six MKS 690 Baratrons used to measure the pressure at various locations on the manifold. There are four 10,000 torr Baratrons, a 1000 torr Baratron, and a 1 torr Baratron. Surface mount thermocouples were attached to the manifold and pumps at various locations to monitor the temperature during testing. The volume of each 50 foot section of $\mathrm{Cu}$ tubing was approximately $3.5 \mathrm{~L}$. The volume of the system without any $\mathrm{Cu}$ tubing was approximately $100 \mathrm{~mL}$.

The experimental manifold instruments were connected to a LabVIEW Data Collection System for pressure transducers, thermocouples, and flow controller data collection. The LabVIEW program was also used to supply the set points for the flow controllers. 


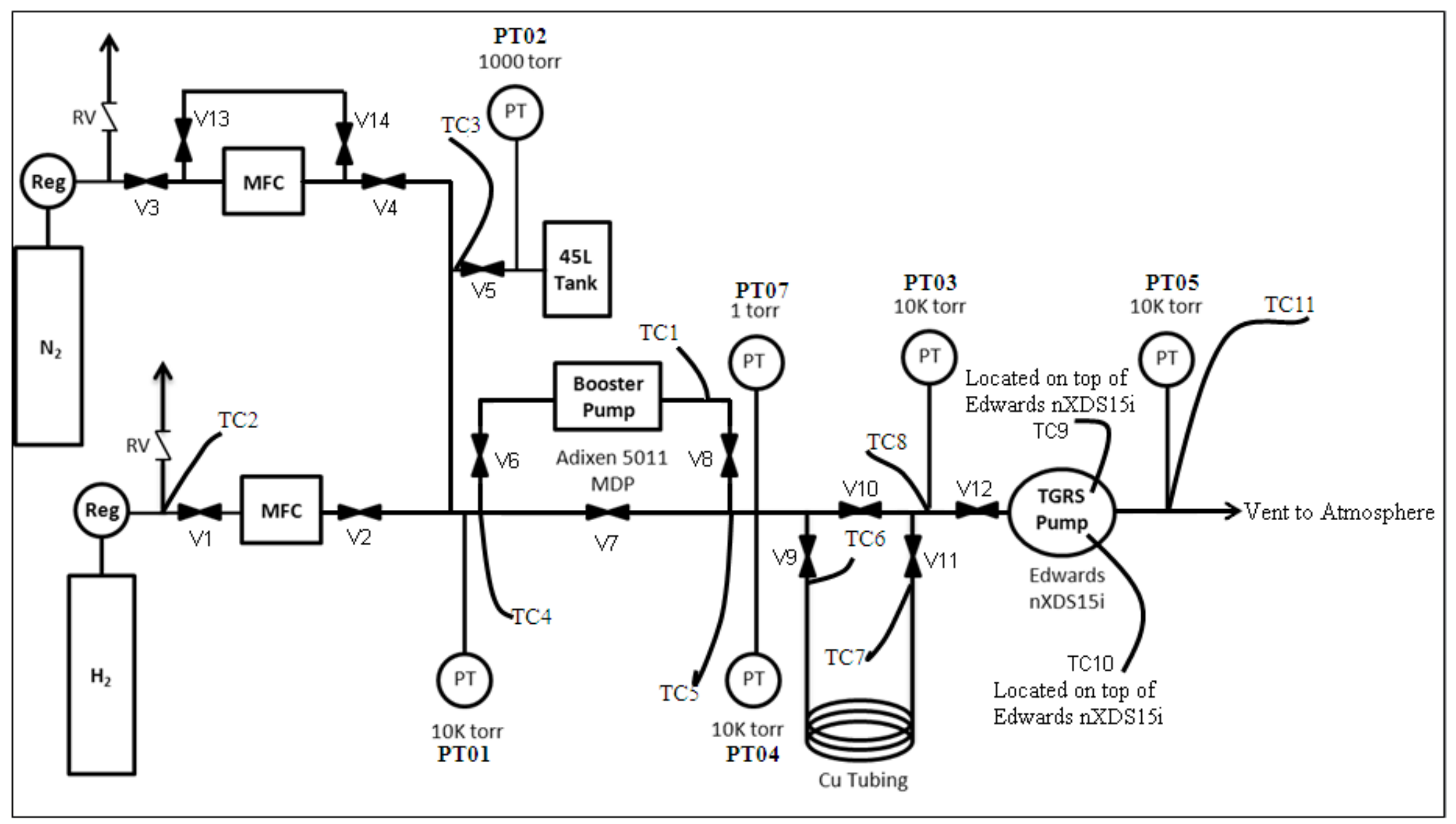

Figure 2-1: SHINE Vacuum Pump Test Manifold Schematic 


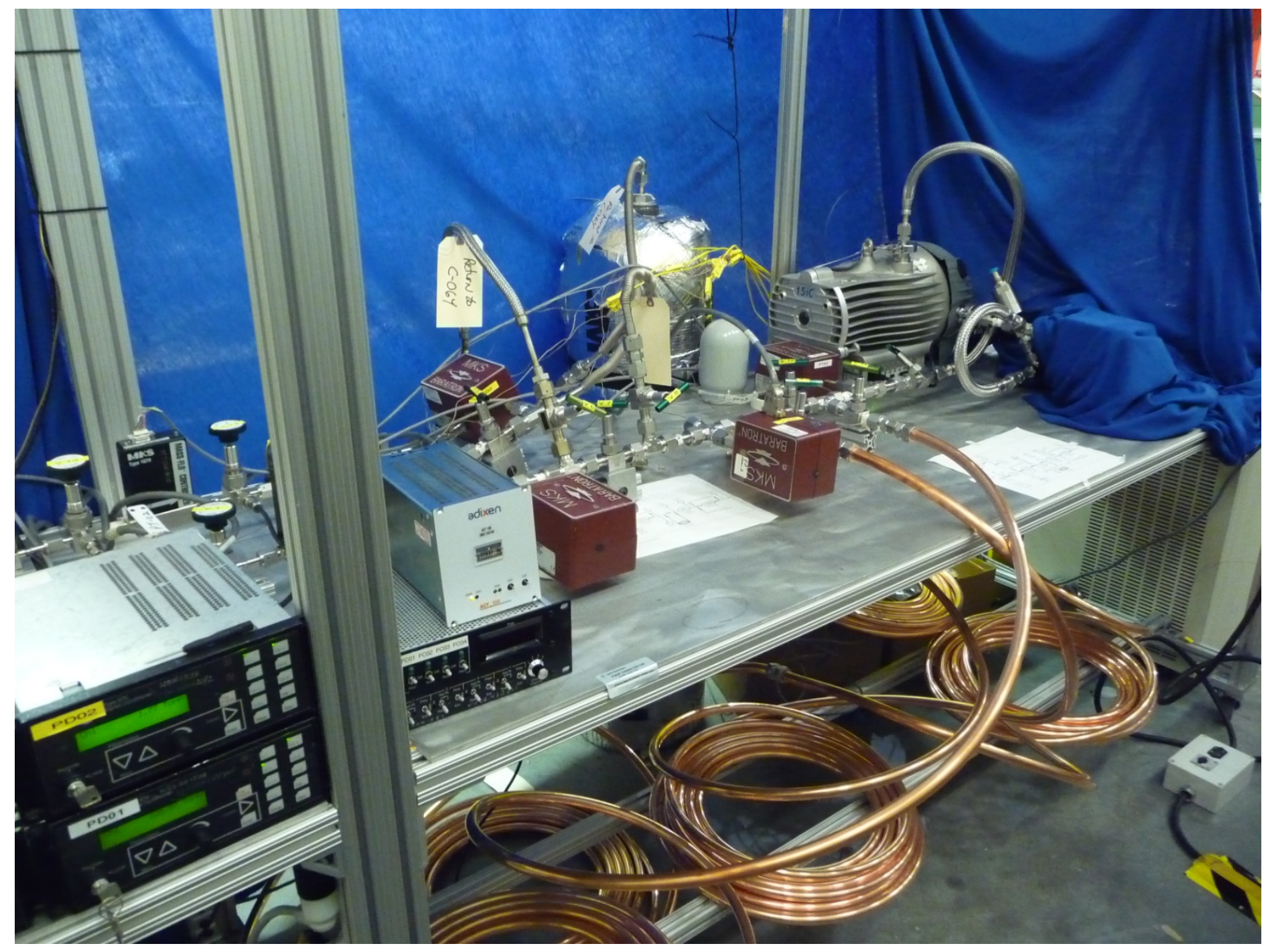

Figure 2-2: SHINE Vacuum Pump Test Manifold 


\subsection{Experimental Testing}

Various tubing and pumping configurations were tested. The details of each configuration will be discussed in detail within the next section of this report. During each test, the desired flow rate through the MFC was set and the system pressures were recorded via the integrated LabVIEW data collection program. Once a stable pressure was obtained, the flow rate was increased to the next set point value. The various configurations were tested using hydrogen and nitrogen at flow rates ranging from 25-400 sccm. All pump testing was non-radioactive (non-tritium) testing, using protium as an adequate surrogate for the tritium-deuterium gas mixtures to be used within the SHINE process.

The Mass Balance Report (6) showed that for each accelerator to maintain a tritium target composition of $\geq 90 \%$, the total effluent tritium rate from the ATIS can vary from $25 \mathrm{sccm}$ (under standard conditions) to $200 \mathrm{sccm}$ if all 8 of the accelerators are operating simultaneously. Therefore, the pump design for TGRS must be capable of maintaining the described flow rates at pressures of 0-30 torr in the 300 feet of line between the ATIS and TGRS.

The current candidate "booster" pump to be evaluated is the Adixen 5011 MDP, which will discharge to the TGRS vacuum pump (with or without a MB backing pump). Vendor literature states the maximum continuous inlet pressure for the pump is 10 mbar (7.5 torr) nitrogen and a maximum exhaust pressure of 40 mbar (30 torr). The TGRS vacuum pump currently being evaluated for possible Normetex ${ }^{\circledR}$ replacement is the Edwards nXDS15iC scroll pump. To ensure that the Adixen 5011 MDP will function as required for ATIS/TGRS operation, the Adixen 5011 MDP will be fed $\mathrm{H}_{2}$ or $\mathrm{N}_{2}$ at a starting flow rate of $25 \mathrm{sccm}$ and increased to $400 \mathrm{sccm}$ in increments of 25 to $50 \mathrm{sccm}$. These flow rates will be used to test each pumping configuration described in section 2.3 below

\subsection{Pumps and Pump Configurations}

As previously discussed and shown in Figure 2-1, there are several pumps and pumping configurations to be tested. Currently, the design of the system allows for two different pumping configurations, and will incorporate six different lengths of tubing, with each tubing length and pumping configuration tested at 12 flow rates. Upon completion of the initial tests without additional line lengths, copper tubing was connected, in 50 foot increments, between the Adixen 5011 MDP (booster pump) and the Edwards nXDS15iC (dry scroll pump). After each tubing addition, each pump configurations was tested at the various flows. This series of tubing addition and testing continued until 300 feet of tubing was connected to the system. Each of the various configurations was tested at flow rates of $25,50,75,100,125,150,175,200,250,300,350$, and $400 \mathrm{sccm}$.

There are four potential pump test configurations. The first two are without the use of the MB pump backing the Edwards XXDS15iC pump:

1. Configuration 1: The Adixen 5011 MDP followed by the Edwards nXDS15iC pump without the MB backing pump. The exhaust of the Edwards pump discharged directly to atmosphere through roughly 30 feet of $1 / 2$ " copper tubing.

2. Configuration 2: The Adixen 5011 MDP bypassed with gas flow directly to the Edwards nXDS15iC pump without the MB backing pump. The exhaust of the Edwards pump discharged directly to atmosphere through roughly 30 feet of $1 / 2$ " 
copper tubing. These data are useful for the evaluation of the Edwards nXDS15iC pump without the use of the "booster" pump.

There are two additional pump test configurations that would use the MB pump to back the Edwards nXDS15iC pump:

3. Configuration 3: All 3 pumps will be used during this configuration; the Adixen 5011 MDP "booster", the Edwards nXDS15iC, and the MB pump. This test configuration would result in a reduced pressure on the back (outlet/discharge) of the Edwards nXDS15iC. The reduced pressure on the back side of this pump would reduce the tritium partial pressure on the Edwards nXDS15iC components with the expected benefit being an extension of the service life of the pump.

4. Configuration 4: This configuration will have the Adixen 5011 MDP bypassed with gas flow directly to the Edwards nXDS15iC pump backed by the MB pump. This pumping configuration is similar to Configuration 2 listed above and will again allow for the evaluation of the reduced pressure between the two pumps..

Non-flow pressure transient measurements (i.e., pump down times) were also examined during each pumping configuration. Pump down times were measured by pressurizing a nominal $45 \mathrm{~L}$ tank to approximately 980 torr using $\mathrm{N}_{2}$ or $\mathrm{H}_{2}$ and measuring the time required to evacuate the tank to a pressure typically less than 1 torr. The pump down tests were completed using only the Edwards scroll pump for each length of Cu tubing.

\subsection{Edwards nXDS15iC Pump Pressure Rating and Compression Testing}

Additional tests performed on the Edwards nXDS15iC pump included a pump pressure rating test and limited compression ratio tests. Compression ratio testing was performed on the pump prior to the pressure rating test that pressurized the pump to failure. Compression ratio tests included controlling discharge pressures of the pump using a Metal Bellows (MB-601) pump with the inlet of the pump blocked, pumping gas from a 100 liter volume with the outlet of the Edwards pump blocked, and pumping with both the inlet and outlet of the Edwards pump blocked.

\subsection{Results and Discussion}

\subsection{Pressure/Compression Test Results}

Several tests were performed to measure the compression ratio $\left(\mathrm{P}_{\text {discharge }} / \mathrm{P}_{\text {suction }}\right)$ for the Edwards nXDS15iC scroll pump. These tests included pumping from a volume with the Edwards pump discharge blocked, using another vacuum pump on the discharge of Edwards pump to vary its discharge pressure while the inlet of the Edwards pump was blocked, and operating the Edwards pump with its inlet and outlet ports blocked.

Results from these tests established that the maximum discharge pressure of the Edwards nXDS15iC pump is approximately 38.5 psia when pumping from atmospheric pressure (760 torr) or below, and that the Edwards nXCS15iC pump's inlet is sealed well from the outlet by the inlet scroll tip sealing material or the internal check valve of the pump. 


\subsubsection{Pumping Using the MB-601 Pump to Vary Discharge Pressure (with inlet blocked)}

Figure 3-1 is a schematic of the compression pump test setup that uses the metal bellows pump (MB-601) to vary the discharge pressure of the Edwards nXCS15iC while the inlet of the Edwards pump was blanked off.

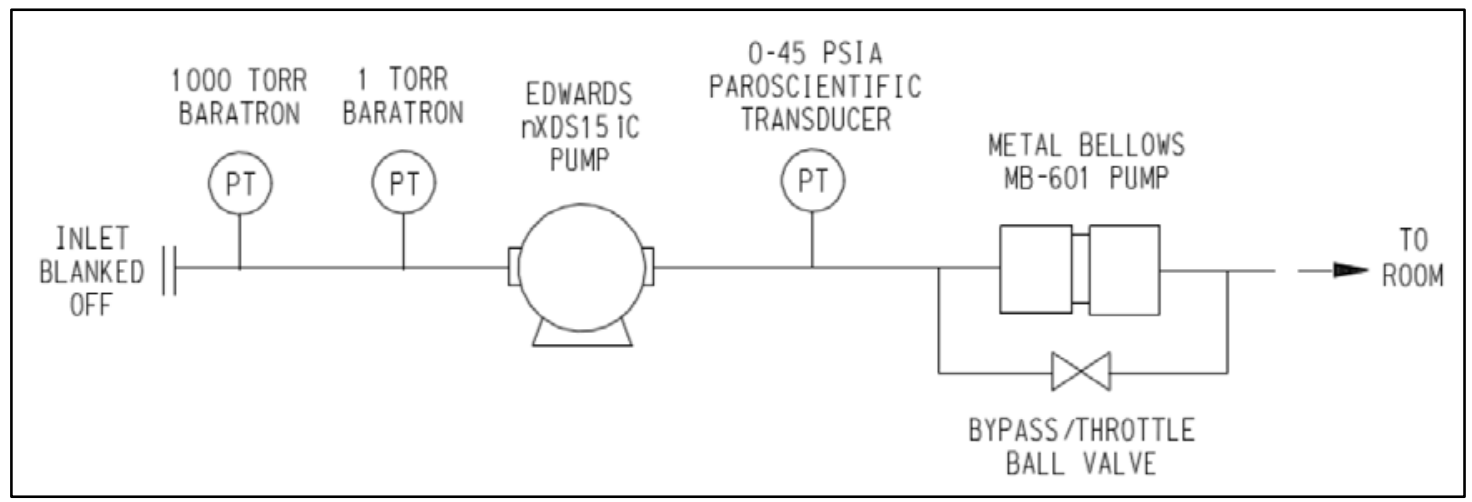

Figure 3-1: Edwards nXDS15iC Pump Test Setup Schematic with inlet blanked off

For these tests, the outlet of the Edwards pump was evacuated by the use of the MB-601 pump and then the Edwards pump turned on to evacuate the inlet of the Edwards pump. Under these conditions, the discharge pressure of the Edwards pump was 7.2 psia (or 372 torr). This discharge pressure was achieved before the Edwards pump was turned on and was maintained after full startup of the Edwards pump. Then, the Metal Bellows pump bypass valve was throttled to achieve different discharge pressures of the Edwards pump. Table 3-1: shows the results from these tests.

Table 3-1: Edwards pump suction blanked off using metal bellows backing pump.

\begin{tabular}{|cccc|}
\hline $\begin{array}{c}\text { Measured Suction } \\
\text { Pressure (mtorr) }\end{array}$ & $\begin{array}{c}\text { Measured Discharge } \\
\text { Pressure (psia) }\end{array}$ & $\begin{array}{c}\text { Discharge Pressure } \\
\text { (torr) }\end{array}$ & $\begin{array}{c}\text { Compression Ratio } \\
\left.\mathbf{( P}_{\text {discharge }} / \mathbf{P}_{\text {suction }}\right)\end{array}$ \\
43.0 & 7.20 & 372 & 8651 \\
43.3 & 9.70 & 501 & 11570 \\
43.8 & 10.22 & 528 & 12055 \\
46.0 & 11.83 & 612 & 13304 \\
47.5 & 12.94 & 669 & 14084 \\
48.5 & 13.40 & 693 & 14288 \\
49.9 & 14.01 & 724 & 14509 \\
50.5 & 14.24 & 736 & 14574 \\
50.8 & 14.42 & 746 & 14685 \\
\hline
\end{tabular}

The data show the inlet pressure of the Edwards nXDS15iC scroll pump varies slightly with different discharge pressures. It is uncertain if this was a result of the polymeric tip seal material between the scroll impellers which creates a good seal between the inlet and outlet of the pump, the result of the check valve on the discharge of the pump, or both. 


\subsubsection{Pumping with a Blocked Inlet and Discharge Side of the Pump}

The Edwards nXDS15iC pump was also operated with the suction and discharge ports blocked on the pump. A schematic of this pump test setup is shown in Figure 3-2.

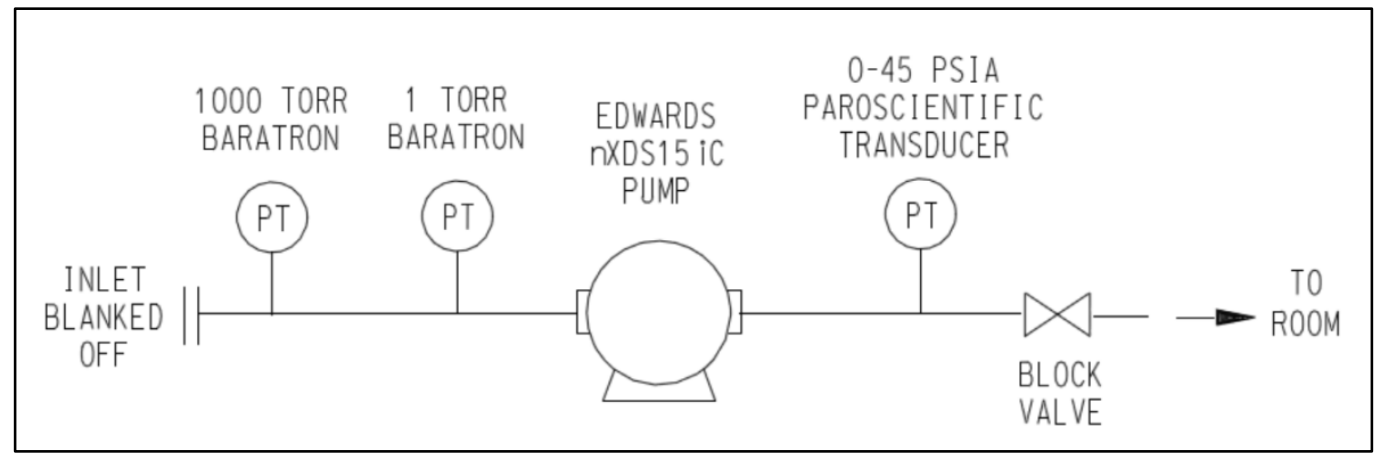

Figure 3-2: Edwards nXDS15iC Pump Test Setup Schematic with Inlet and Discharge Blocked

Table 3-2 shows results from this type of testing. The first entry in the table resulted from only using the inlet line volume necessary to connect the pressure transducers. The second table entry was obtained when a 100-L volume was connected to the inlet of the pump. The ultimate suction pressure is a function of the volume of air available on the suction side of the pump and limited by the fact that the pump is able to create a maximum discharge pressure of 38.5 psig (1991 torr) with an inlet pressure of 760 torr.

Table 3-2: Edwards Pump Inlet and Discharge Ports Blanked Off

\begin{tabular}{|cccc|}
\hline $\begin{array}{c}\text { Measured Suction } \\
\text { Pressure (torr) }\end{array}$ & $\begin{array}{c}\text { Measured Discharge } \\
\text { Pressure (psia) }\end{array}$ & $\begin{array}{c}\text { Discharge Pressure } \\
\text { (torr) }\end{array}$ & $\begin{array}{c}\text { Compression Ratio } \\
\left(\mathbf{P}_{\text {discharge }} / \mathbf{P}_{\text {suction }}\right)\end{array}$ \\
476 & 38.5 & 1991 & 4.2 \\
731 & 38.5 & 1991 & 2.7 \\
\hline
\end{tabular}

\section{2 $\underline{\text { Pressure Test }}$}

The Edwards pump was placed in a pressure test chamber (known as the walk-in gun barrel) and 25 psig of nitrogen was initially applied to the pump. Pressure to the pump was increased in 25 psig increments, stopping at each increment to verify the absence of pump or system leakage. This procedure was repeated until the pump was found to leak or until failure. During pressure testing, there was no evidence of leakage from the pump until complete pump failure was realized at 208 psig. The following are pictures of the pump prior to (Figure 3-3) and after (Figure 3-4) pressure testing. 


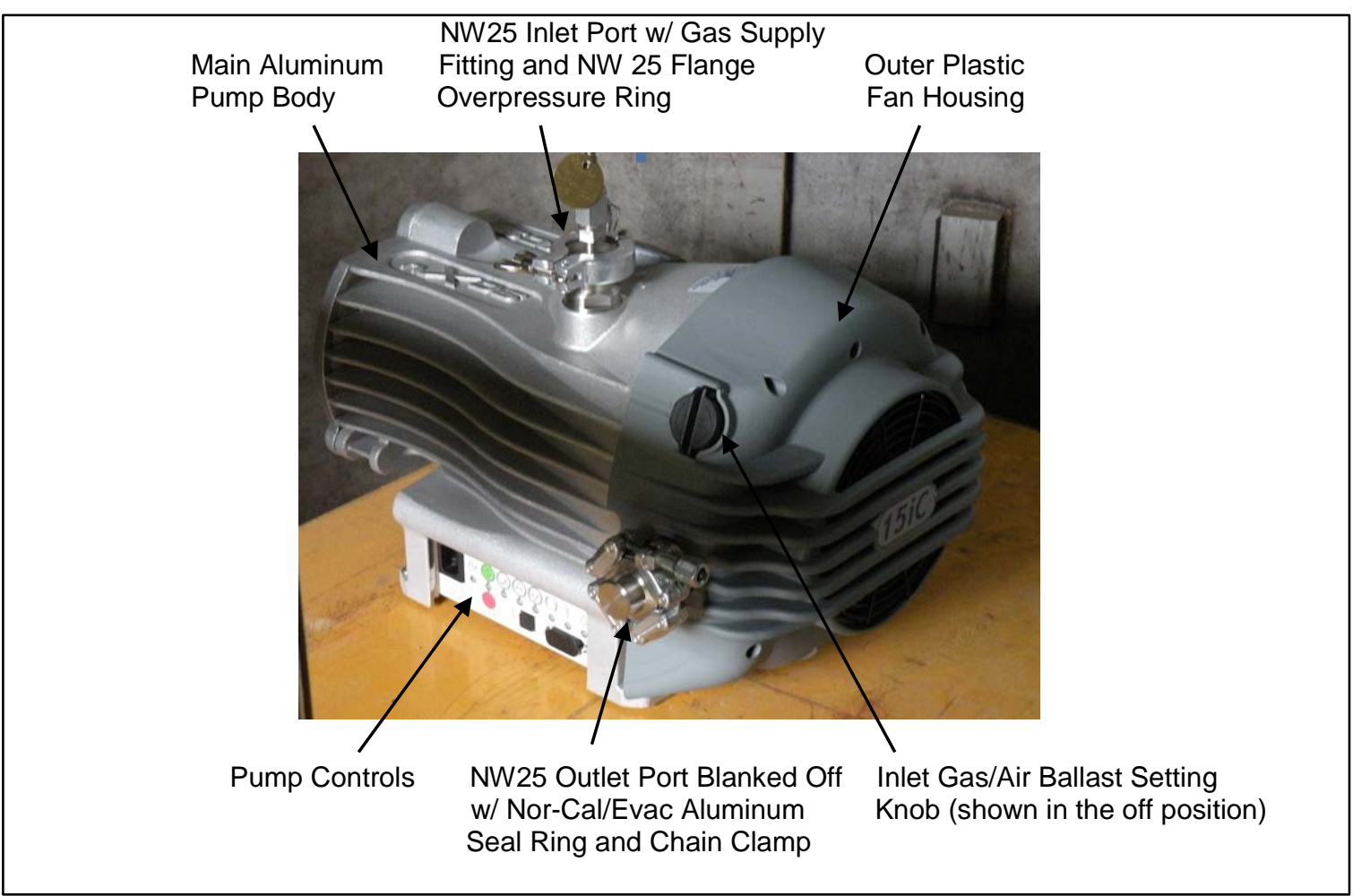

Figure 3-3: Edwards nXDS15iC Scroll Pump in 723-A Walk-in Gun Barrel

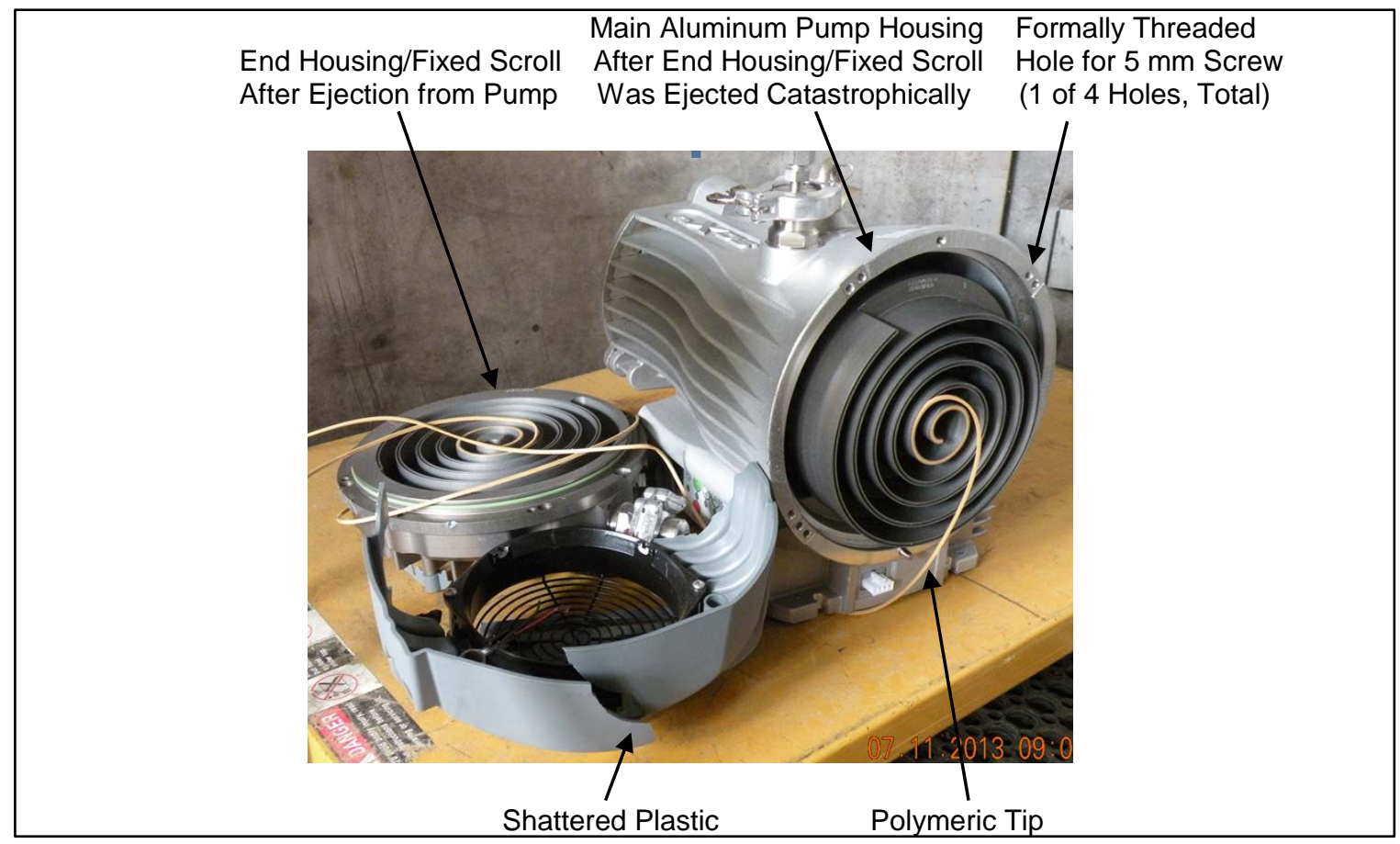

Figure 3-4: Edwards nXDS15iC Scroll Pump after Pressure/Burst Testing 
Failure of the pump was a result of four $5 \mathrm{~mm}$ screws that hold the end housing/fixed scroll to the main pump casing being "stripped" from their aluminum threaded holes in the main pump casing. The main pump casing is made from aluminum with "cut" rather than "rolled" threads, causing a high stress area and a structural weak point. It was in this location that the threads failed as a result of the pressure loading.

\subsection{Manifold Experimental Results}

\subsubsection{Dynamic Flow Testing}

Initially short term dynamic flow tests were completed for the various configurations using $\mathrm{H}_{2}$. The time at each of the hydrogen flow rates was no more than 30 minutes and in some cases was as little as 15 minutes. The corresponding pressure vs. time curves showed no general trend as the flow rate of $\mathrm{H}_{2}$ increased. In some cases, the pressure in the system would increase slightly as the $\mathrm{H}_{2}$ flow rate was increased, but in others the various pressure readings would remain constant (or possibly decrease) with an increase in the $\mathrm{H}_{2}$ flow rate. There was very little correlation between the increase in the $\mathrm{H}_{2}$ flow rate and the observed pressure in the experimental system. A representative sampling of these figures is shown in Figure 3-5 through Figure 3-7.

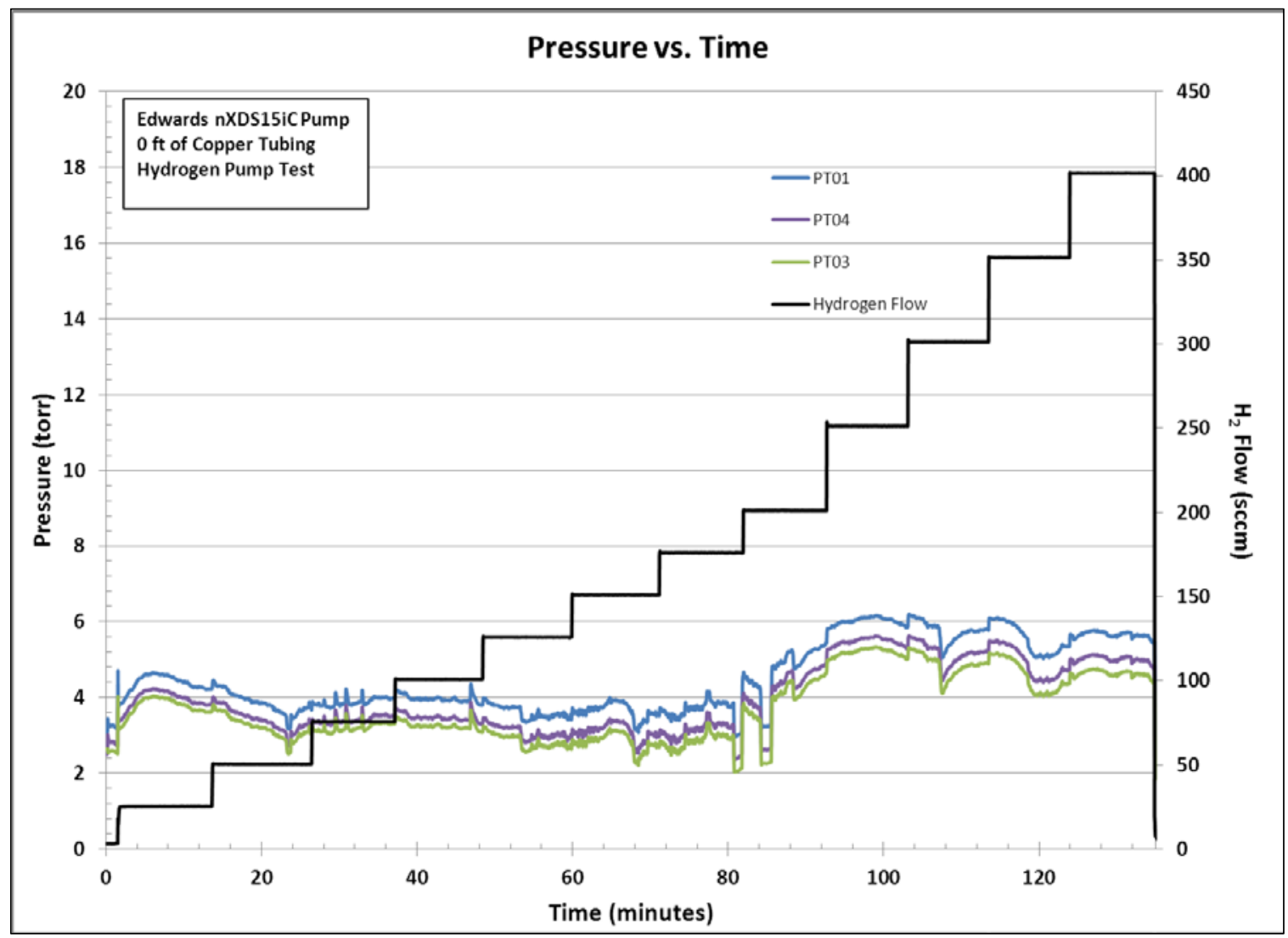

Figure 3-5: Pressure vs. Time plot for hydrogen with the Edwards pump and 0 feet of tubing. 


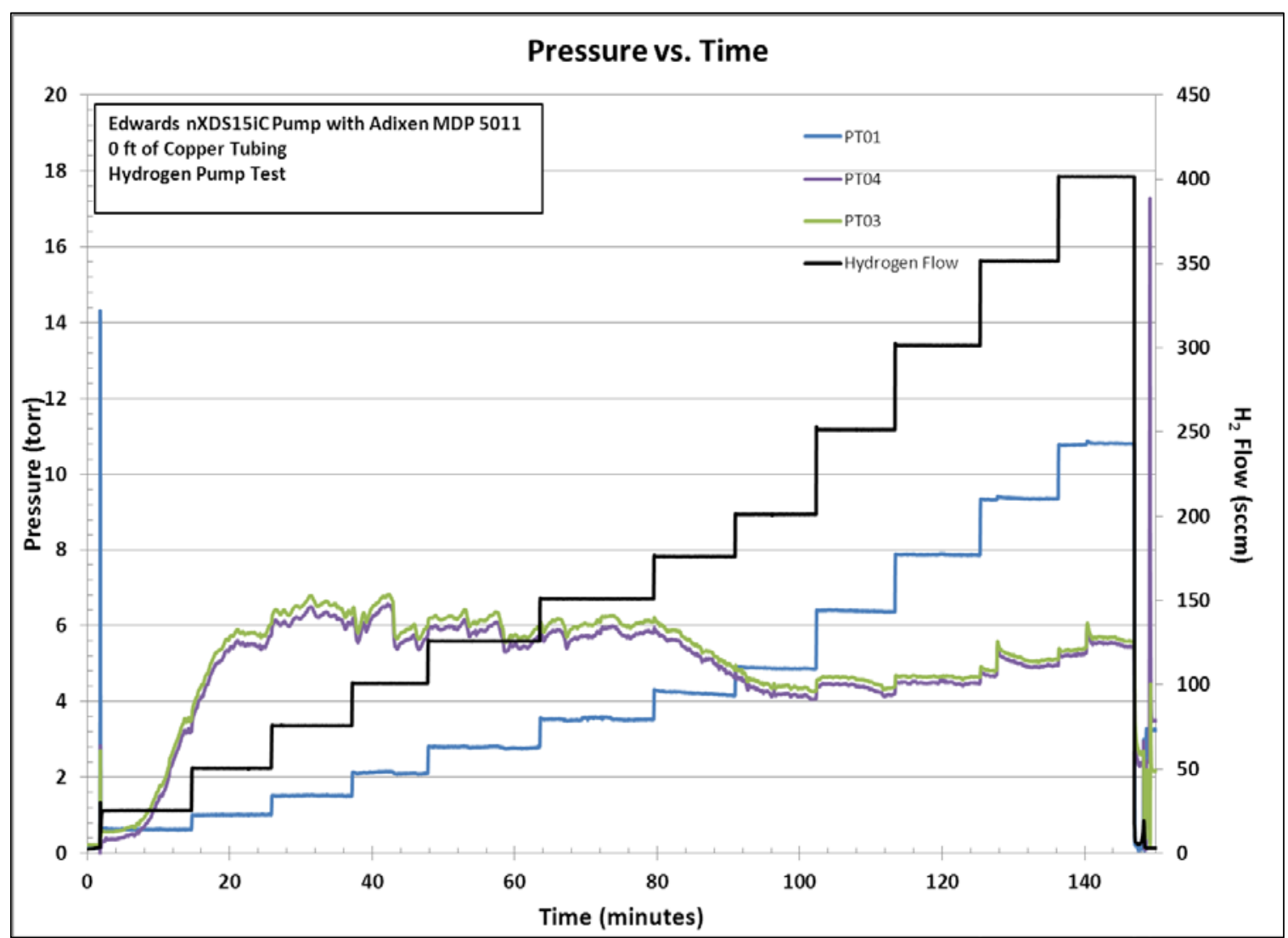

Figure 3-6: Pressure vs. Time plot for hydrogen with the Edwards pump and the Adixen molecular drag pump and 0 feet of tubing. 


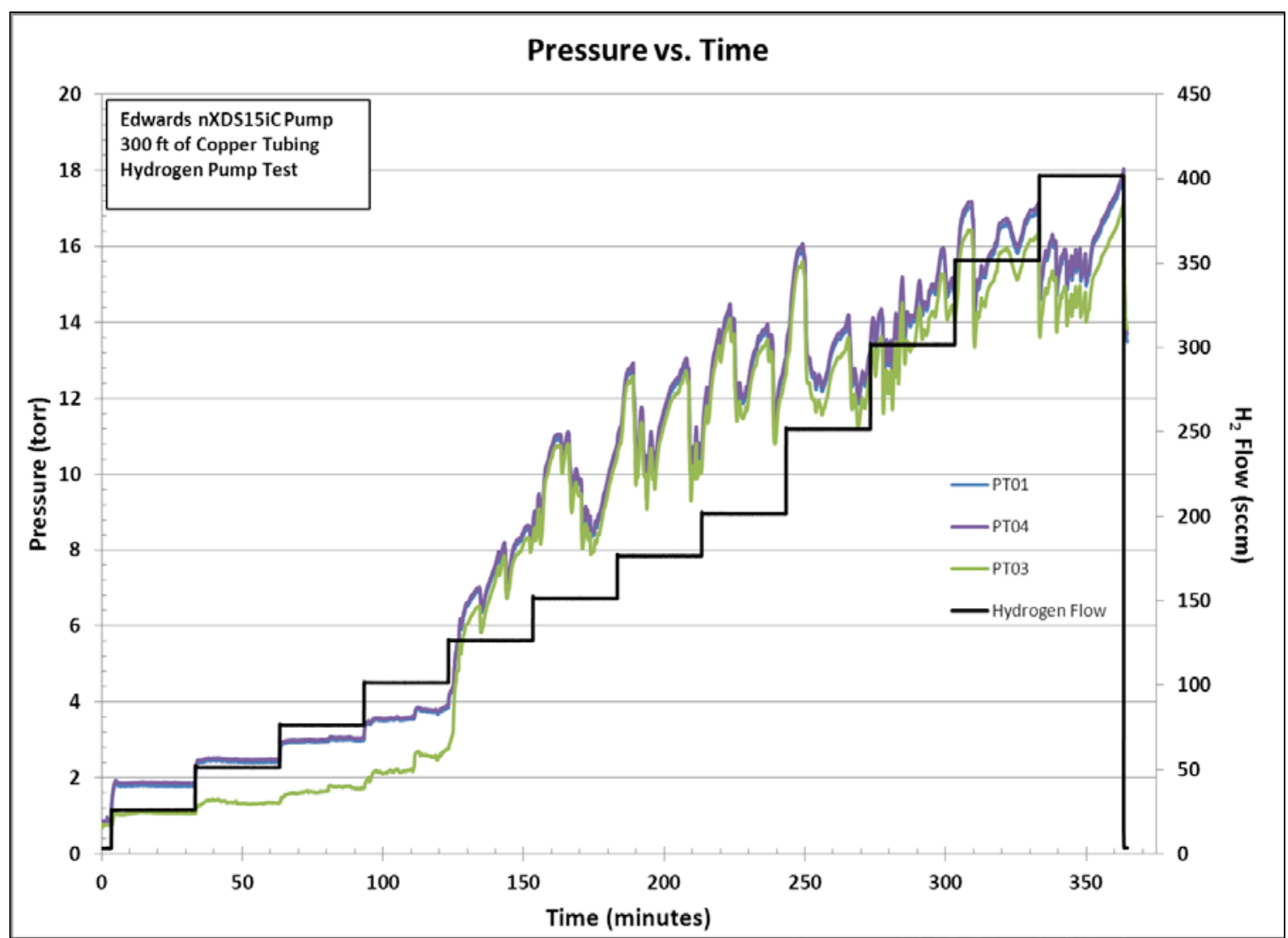

Figure 3-7: Pressure vs. Time plot for hydrogen with the Edwards pump and 300 feet of tubing.

Potential reasons for this observed pressure behavior are:

1. Initially the inlet pressure on the flow controller was set to approximately 50 psig using the gas supply regulator. It was speculated that this pressure may have been too high for stable operation of the control valve on the MKS Mass Flow Controller (MFC) and variations in the down-stream pressure of the MFC created pressure fluctuations that propagated through the system. In the subsequent experimental tests the inlet pressure was lowered to 25 psig.

2. There is a manufacturer installed check valve inside the pump. This check valve may chatter/flutter or may have a dynamic interaction with the pressure oscillations introduced upstream of the pump.

3. The difference in the viscosity between nitrogen and hydrogen may also contribute to the dynamics of system pressure oscillations: the viscosity of air at room temperature is nearly twice the viscosity of hydrogen. The less-viscous hydrogen could contribute to or propagate the pressure oscillations in the system. The back-pressure in the exhaust line that discharges to atmosphere was initially back-filled with nitrogen or air at the start of a test. For later flow tests, the system was purged using the test gas (hydrogen or nitrogen) for 30 minutes at $350 \mathrm{sccm}$ to displace the non-test gas species from the tubing.

4. The relatively short duration of the initial experimental tests may not be adequate for the system to reach equilibrium conditions. For most of the subsequent testing the time at each of the flow rates was increased to several hours (sometimes three or four) to allow adequate time for the system to come to equilibrium. 
The first test configuration incorporated only the Edwards pump with various lengths of copper tubing. Nitrogen and hydrogen were flowed through the system at flow rates up to $400 \mathrm{sccm}$. The pressure vs. time curves for the nitrogen and hydrogen testing showed dramatically different results. When $\mathrm{N}_{2}$ is flowed through the system, there is a step-wise increase in the system pressure for all three pressure transducers. The step-wise increase in the pressure correlates with the increase in the flow rates. This was observed for all lengths $\mathrm{Cu}$ tubing ranging from 0 feet to 300 feet. Representative pressure vs. time plots for 0 feet of copper tubing and 300 feet of copper tubing are shown in Figure 3-8 and Figure 3-9, respectively.

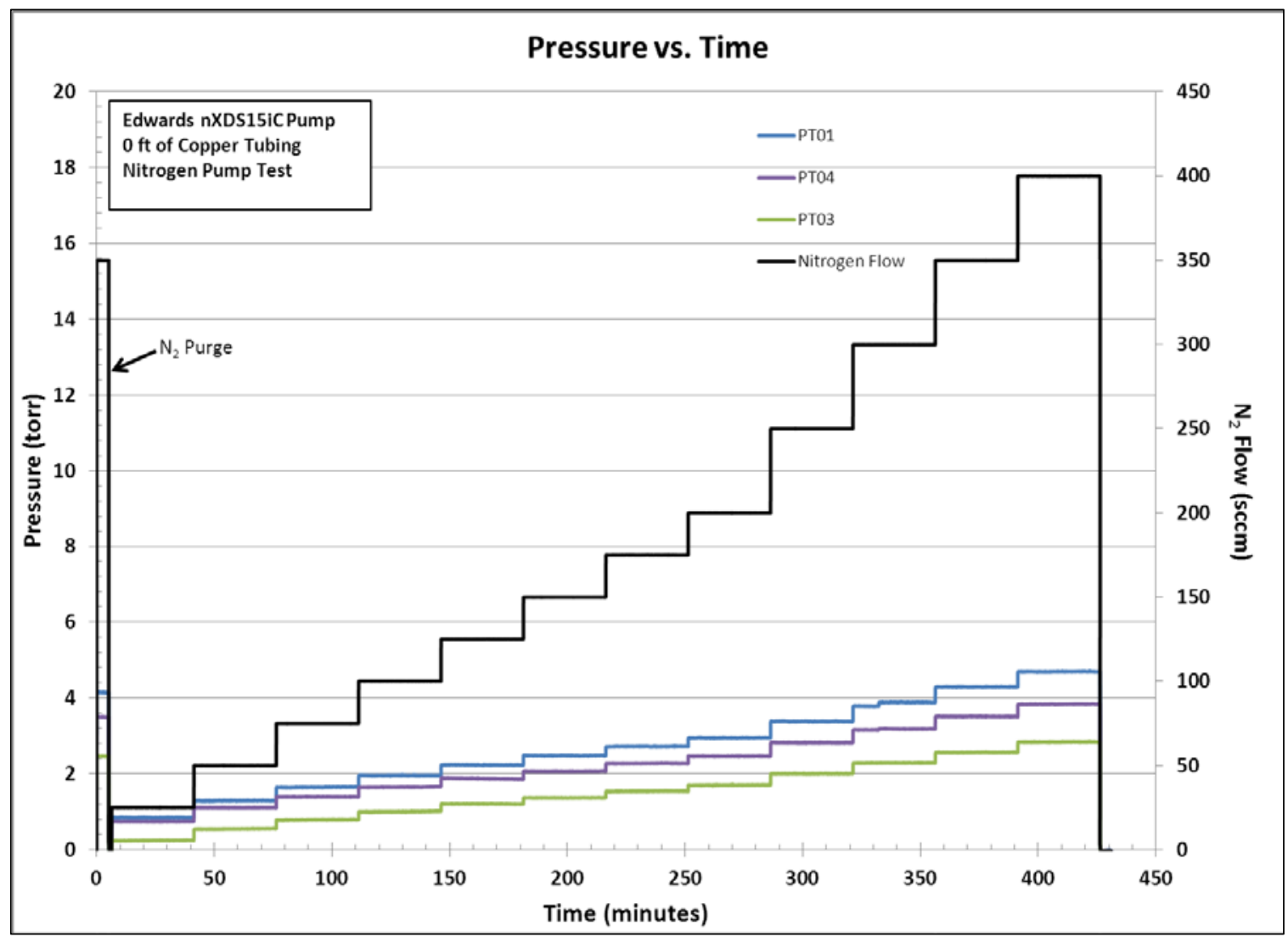

Figure 3-8: Pressure vs. Time plot for nitrogen with the Edwards pump and 0 feet of tubing.

There was approximately a 2 torr pressure drop across the length of the experimental system when 0 feet of copper tubing was tested. PT03 is the closest pressure transducer to the inlet of the Edwards scroll pump and therefore the pressure measured at this point should be the lowest as observed in the various figures. When the test was repeated using 300 feet of copper tubing, there was a larger pressure drop across the experimental system. PT01 which is near the gas inlet of the experimental system (just after the mass flow controllers) increased to $~ 9.5$ torr when 300 feet of copper tubing was used: nearly double the pressure reported with 0 feet of copper tubing installed. The 1 torr pressure drop across valve V7 (PT01 less PT04) at $400 \mathrm{sccm}$ was approximately the same for all lengths of copper tubing. 


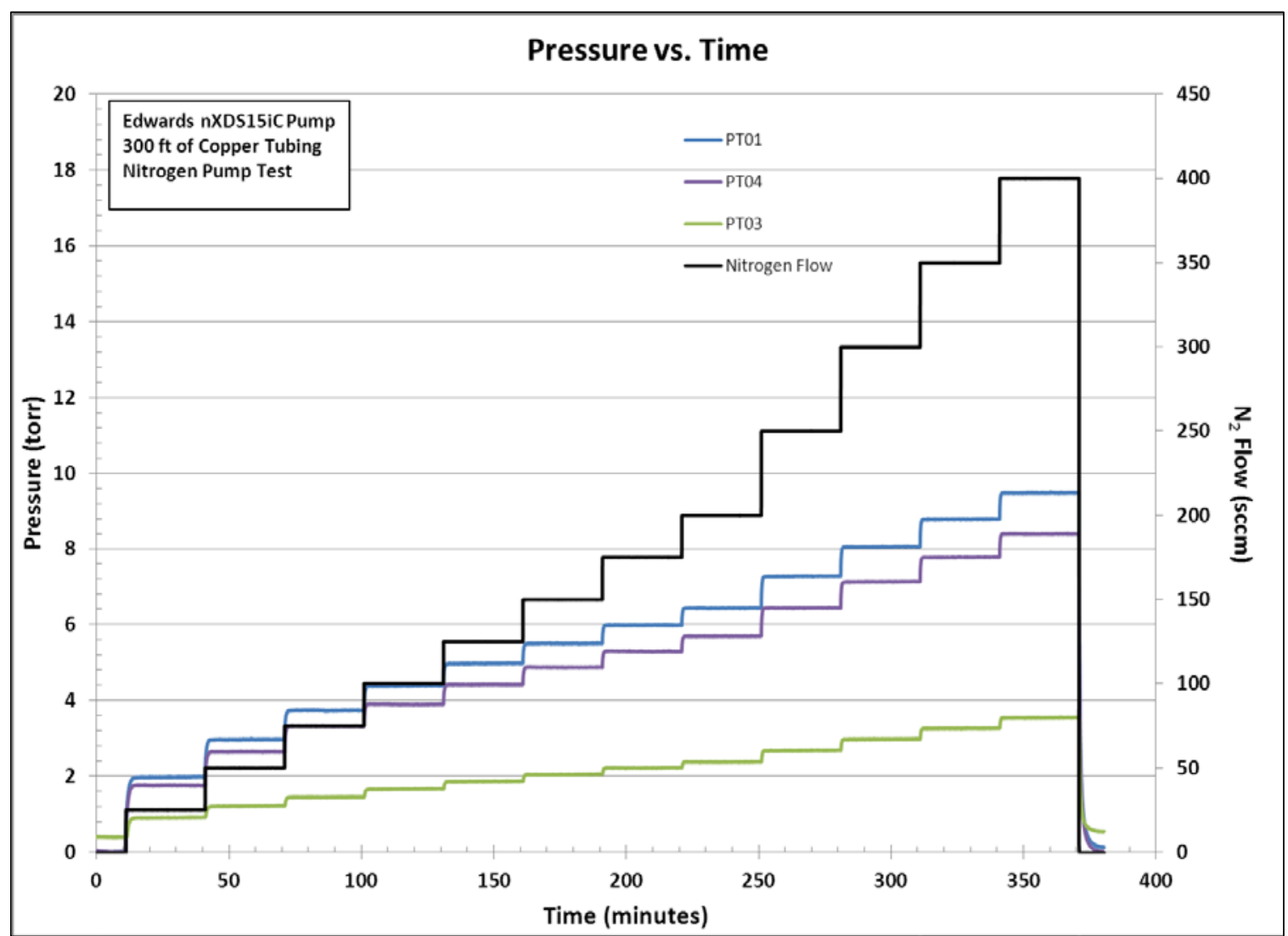

Figure 3-9: Pressure vs. Time plot for nitrogen with the Edwards pump and 300 feet of tubing. 
When $\mathrm{H}_{2}$ was used for testing, there was a general increase in the measured pressure for 0 feet of copper tubing as shown in Figure 3-10. However, there was no pronounced stepwise increase in the pressure as was observed during the $\mathrm{N}_{2}$ testing.

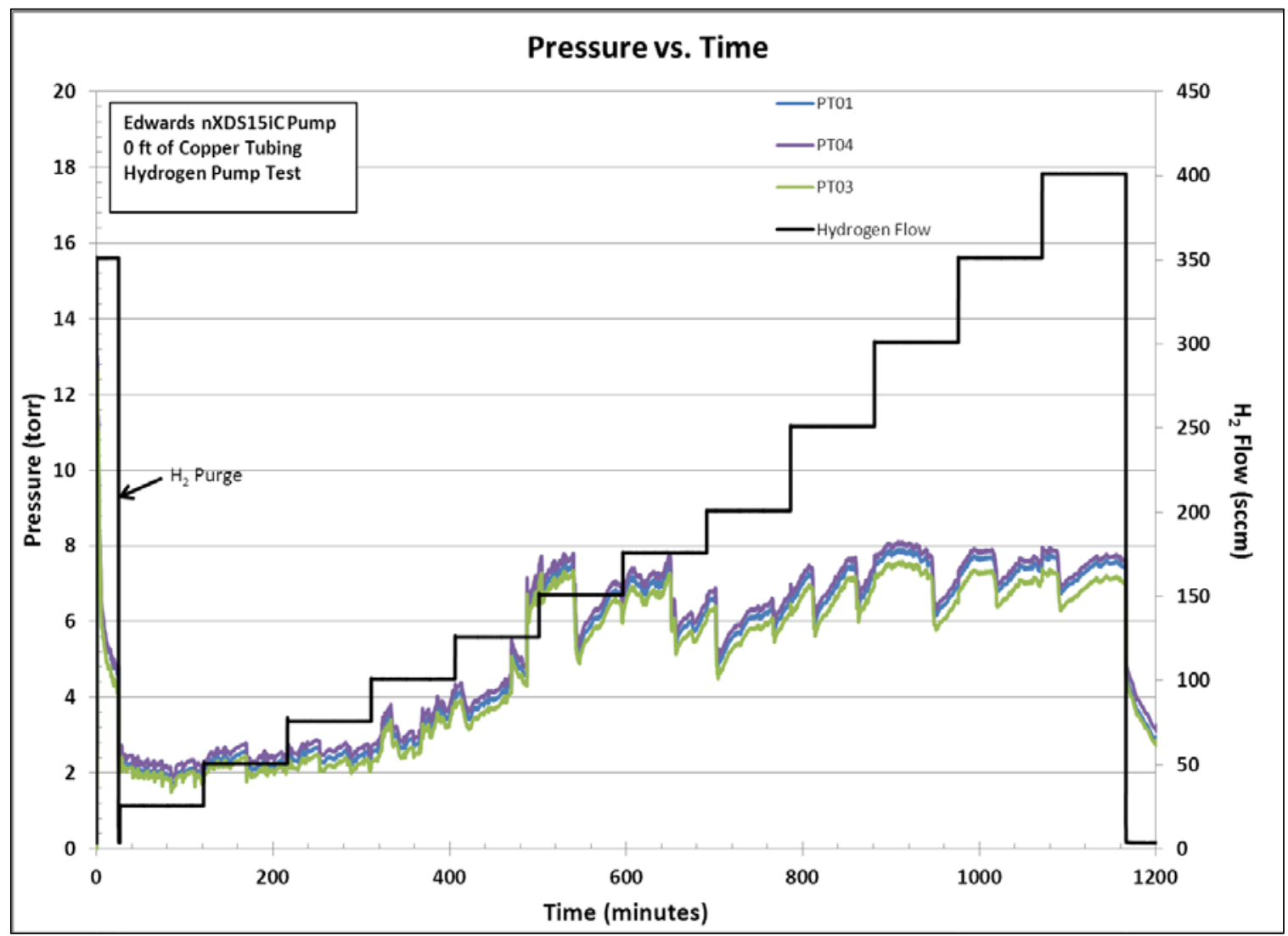

Figure 3-10: Pressure vs. Time plot for hydrogen with the Edwards pump and 0 feet of tubing.

For both 0 feet and 300 feet of tubing, the $\mathrm{H}_{2}$ pressure is roughly the same during the various flow rates, increasing up to $\sim 7-8$ torr at $400 \mathrm{sccm}$. For 0 feet of copper tubing, there was a minimal pressure drop across the system. The three pressure transducers track roughly the same value throughout the sytem. However with 300 feet of copper tubing, there is a pressure drop across the length of the tubing that approaches 2 torr at the highest flow rate. The presure drop is smaller for hydrogen than observed for nitrogen. 
When 300 feet of copper tubing was used with hydrogen as the test gas, there was a slight stepwise profile, as shown in Figure 3-11.. The profile was not nearly as pronounced as when the $\mathrm{N}_{2}$ was used. The system pressures were significantly more stable using $\mathrm{N}_{2}$ compared to $\mathrm{H}_{2}$ for the tests.

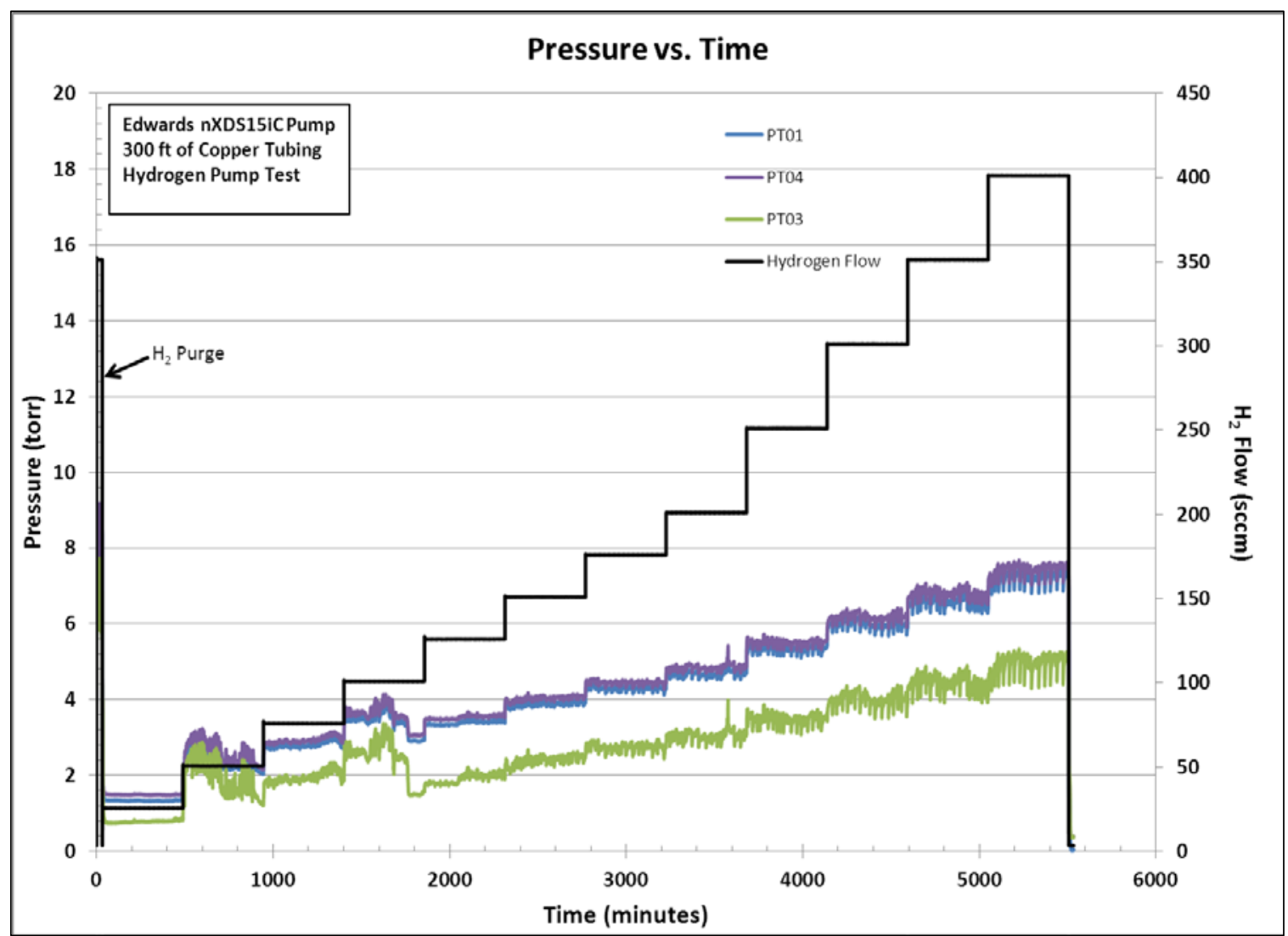

Figure 3-11: Pressure vs. Time plot for hydrogen with the Edwards pump and 300 feet of tubing. 
The results of a long term testing using hydrogen and the Edwards pump with 250 feet of tubing are shown in Figure 3-12. This test was conducted at a single $\mathrm{H}_{2}$ flow rate of $300 \mathrm{sccm}$. The figure shows that for the initial 7 hours of the test that the pressure in the system fluctuates, however after 7 hours of constant flow the pressure in the system becomes very stable as measured by the three transducers.

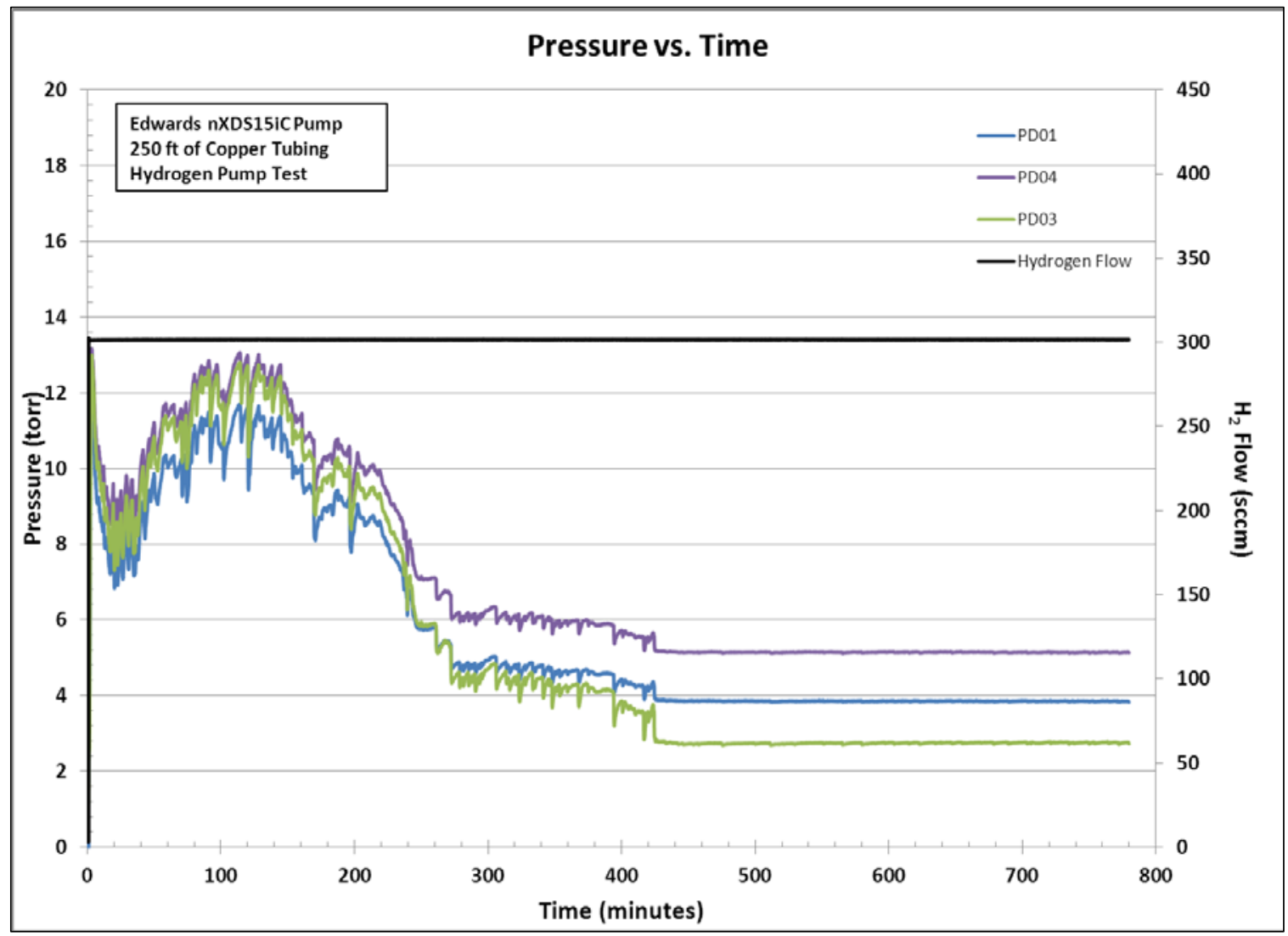

Figure 3-12: Pressure vs. Time plot of hydrogen with the Edwards pump and 250 feet of tubing. 
The second configuration tested was the Edwards nXDS15iC scroll pump backing the Adixen molecular drag pump with various lengths of tubing. The pressure vs. time curves for $\mathrm{N}_{2}$ using 0 feet and 300 feet of copper tubing are shown in Figure 3-13 and Figure 3-14, respectively.

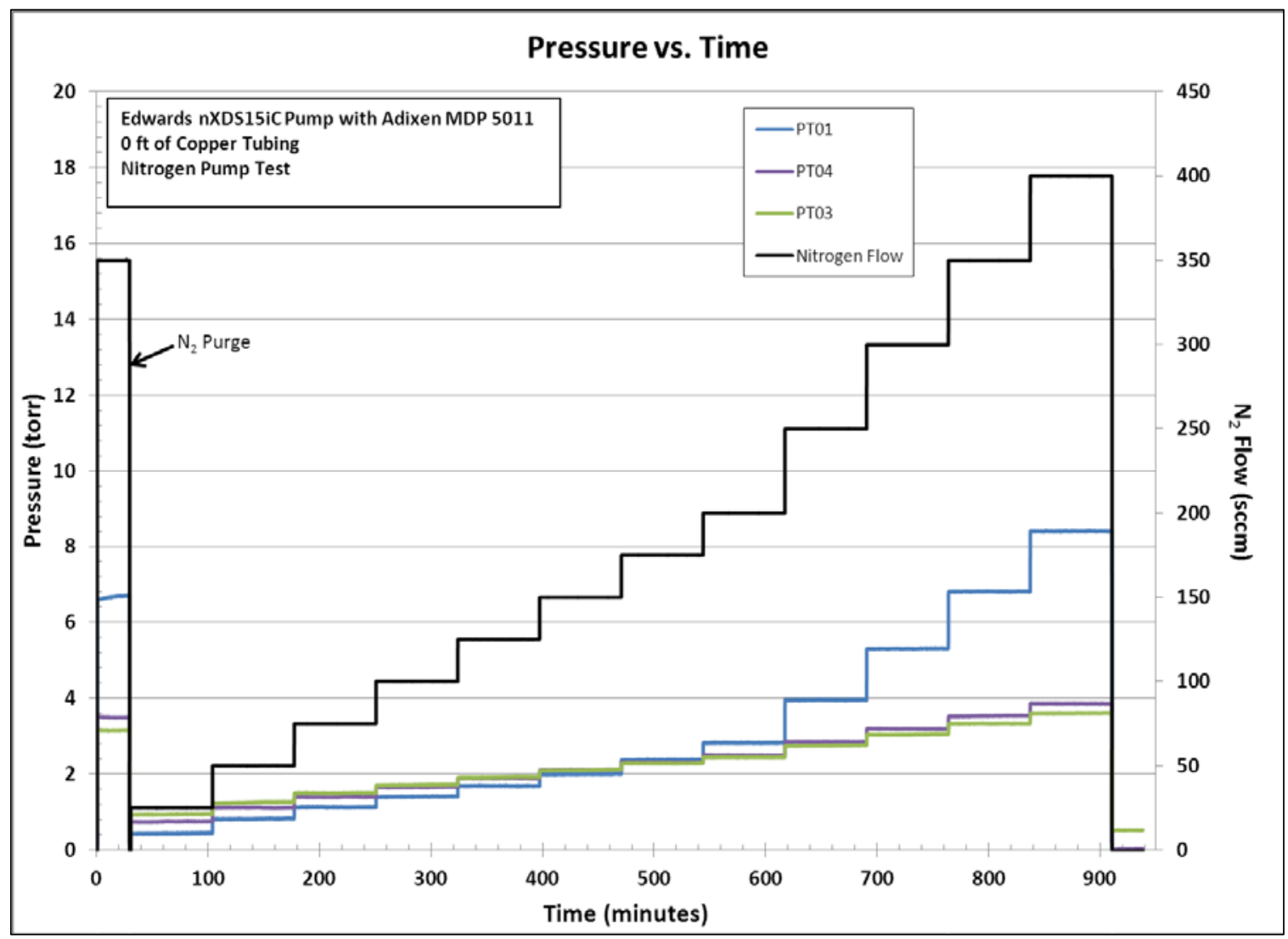

Figure 3-13: Pressure vs. Time plot for nitrogen with the Edwards pump, Adixen molecular drag pump, and 0 feet of tubing.

In both test cases the three pressure transducers exhibit the stepwise profile that correlates with the increase in flow rates for nitrogen. At the higher flow rates, the pressure drop across the system is approximately 4-5 torr across 0 feet of tubing (Figure 3-13). Below flow rates of 200 sccm there is essentially zero pressure drop across the system. In the case with 300 feet of tubing, the pressure drop across the tubing is roughly 6 torr, as shown in Figure 3-14. For all of the flow rates (except $400 \mathrm{sccm}$ where the pressures are equal), the exhaust pressure of the Adixen 5011 MDP is greater than the inlet pressure (PT01). This indicates that the molecular drag pump is able to operate with flow rates up to 400 sccm and a backing pump that is 300 feet away. 


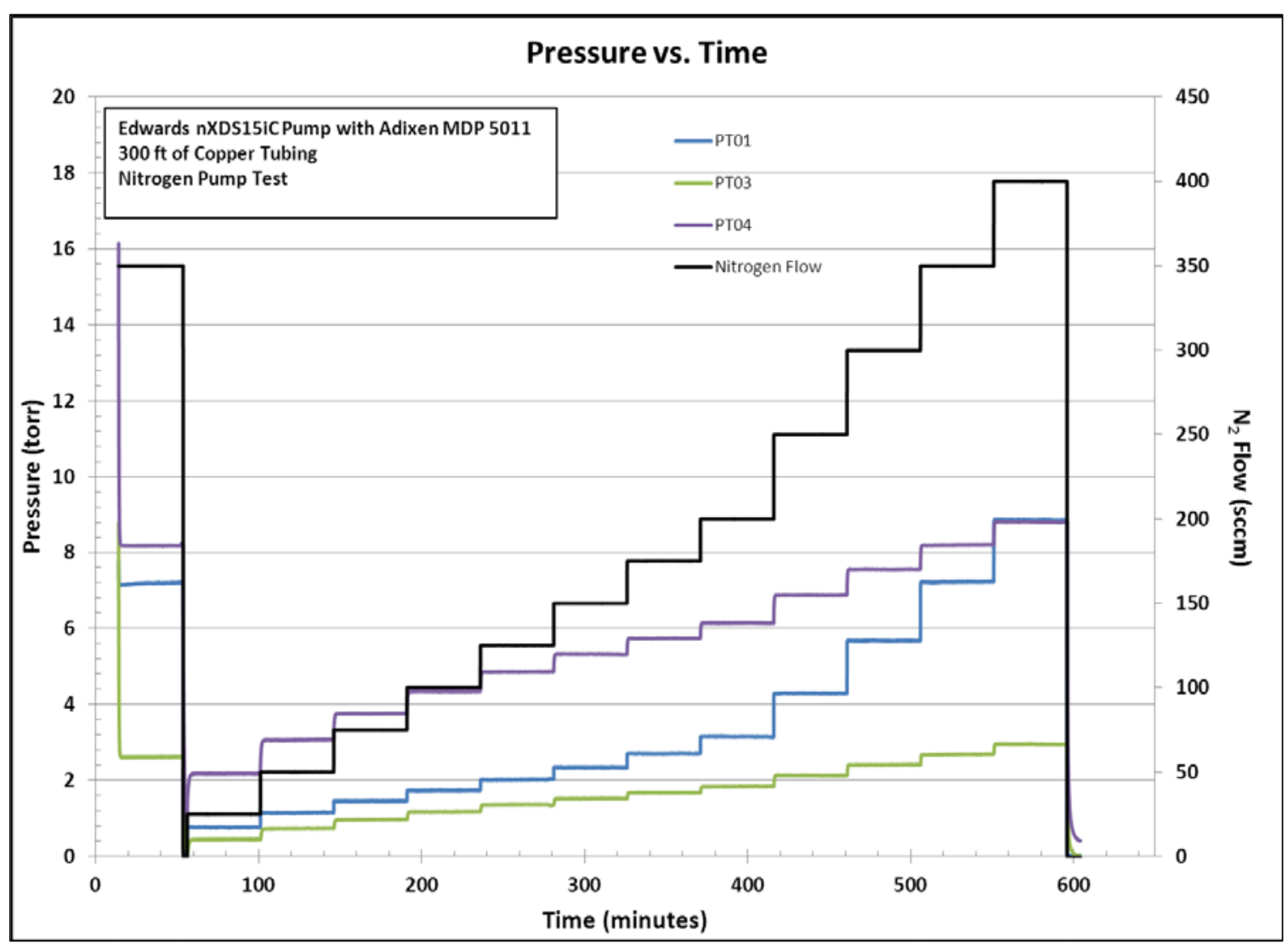

Figure 3-14: Pressure vs. Time plot for nitrogen with the Edwards pump, Adixen molecular drag pump, and 300 feet of tubing. 
The hydrogen test results with the molecular drag pump/Edwards pump combination are shown in Figure 3-15 and Figure 3-16. At 0 feet of tubing, PT01 shows a stepwise increase in the inlet pressure correlating with the increase in the flow rates of hydrogen, as shown in Figure 3-15, however PT03 and PT04 results are sporadic throughout the increase in the test flow rates, but track closely to each other because of the minimal volume between the two measurement points in the system.

The results using 300 feet of tubing (Figure 3-16, show PT01 to have a similar step-wise increase as seen with 0 feet of copper tubing. For 300 feet of tubing, PT03 and PT04 also exhibit stepwise changes corresponding to the increase in the flow rates up to $125 \mathrm{sccm}$. At flow rates higher than $125 \mathrm{sccm}$, as shown in Figure 3-16, there is a general increase in the system pressure as measured by PT03 and PT04.

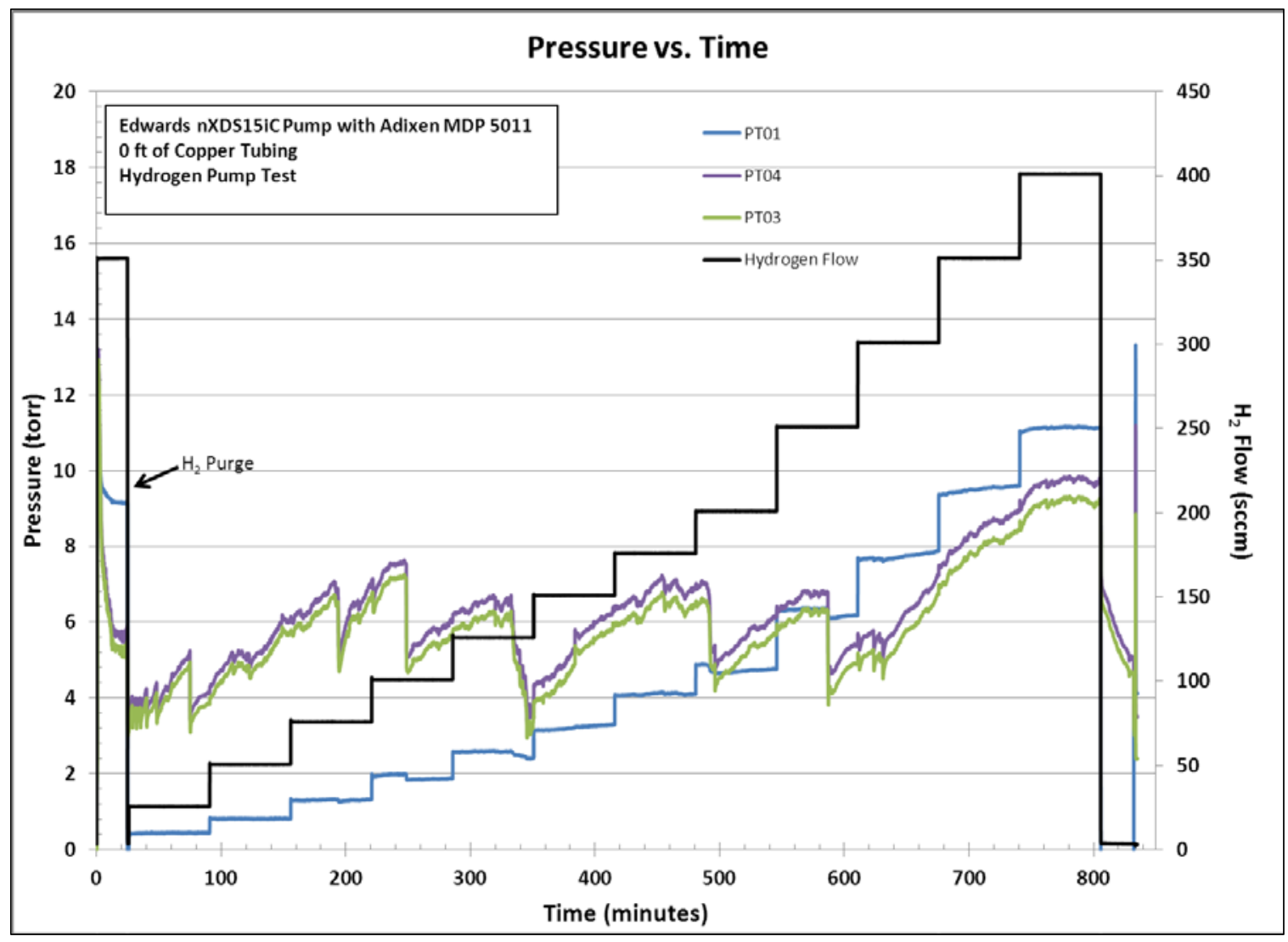

Figure 3-15: Pressure vs. Time plot for hydrogen with the Edwards pump, Adixen molecular drag pump, and 0 feet of tubing. 


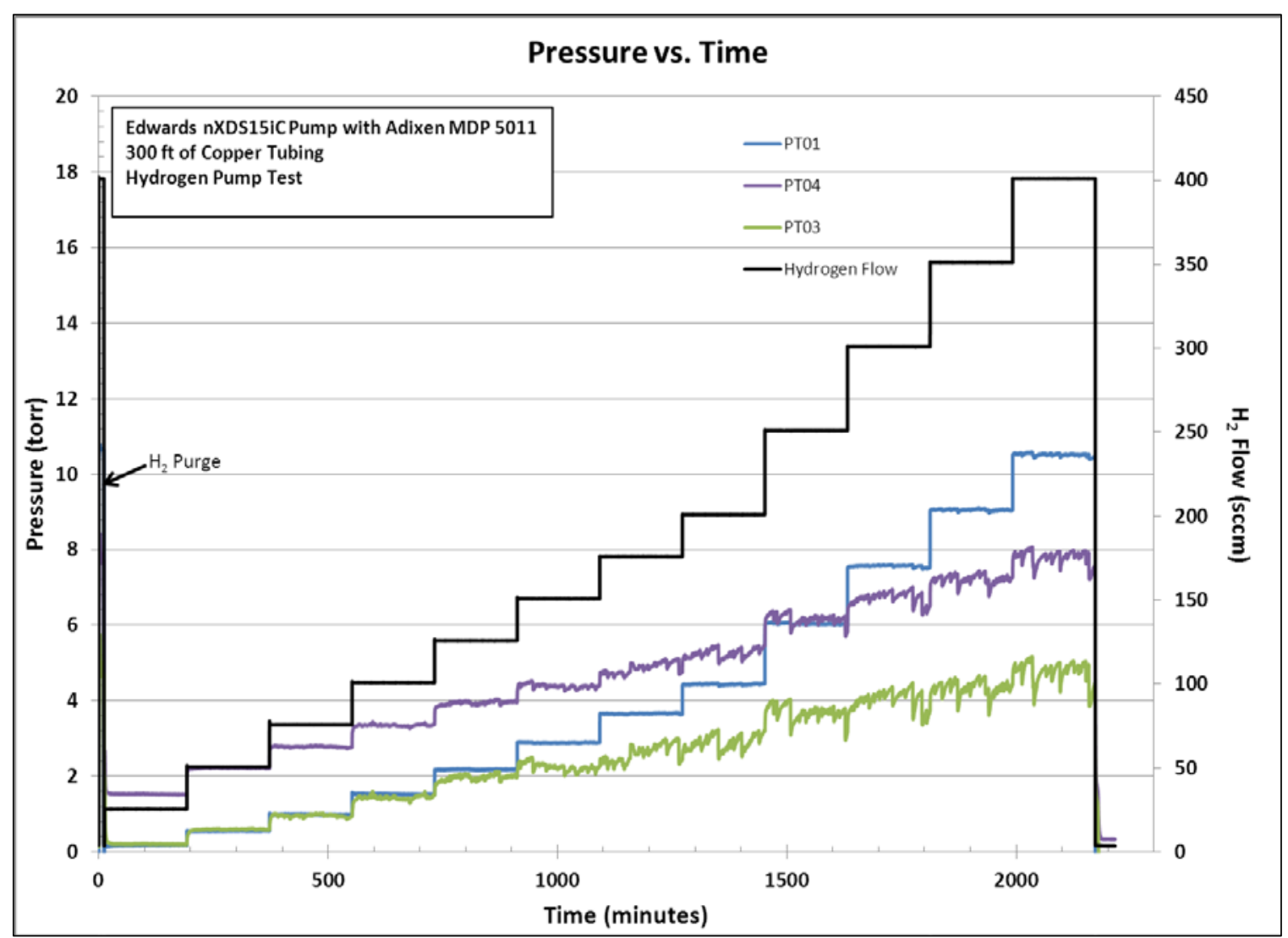

Figure 3-16: Pressure vs. Time plot for hydrogen with the Edwards pump, Adixen molecular drag pump, and 300 feet of tubing. 
Figure 3-17 and Figure 3-18 are representative data plots of the temperature profiles during the various tests. Regardless of the pump configuration and the length of tubing, the Edwards Pump TCs, TC09 and TC10, typically measured approximately $45-46^{\circ} \mathrm{C}$ when hydrogen was flowing through the system, as shown in Figure 3-18. These two thermocouples are located near the inlet of the Edwards pump on the top of the housing. In addition TC01, located at the outlet of the Adixen drag pump, also increased slightly above ambient during the course of the experiment as hydrogen was flowing through the system. When nitrogen is flowing through the system (Figure 3-17) the temperature of the Edwards exhaust housing increases to $\sim 35-36^{\circ} \mathrm{C}$, nearly $10^{\circ} \mathrm{C}$ lower than when hydrogen is flowing through the system. The exhaust outlet of the Adixen molecular drag pump (TC01) increased to approximately $31^{\circ} \mathrm{C}$ even with the cooling fan blowing directly on the housing of the molecular drag pump.

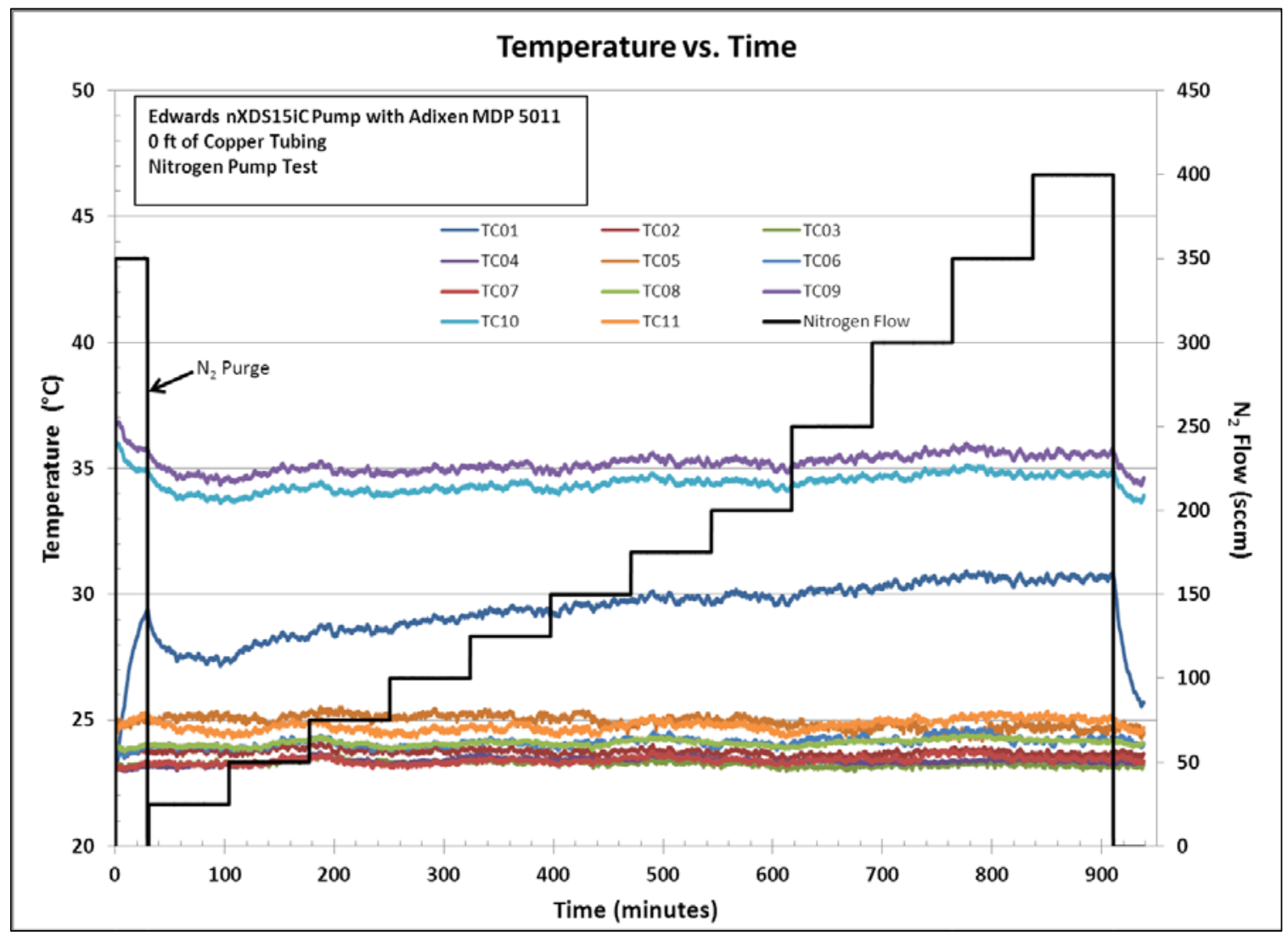

Figure 3-17: Temperature vs. Time plot for nitrogen with the Edwards pump, Adixen molecular drag pump, and 0 feet of tubing. 


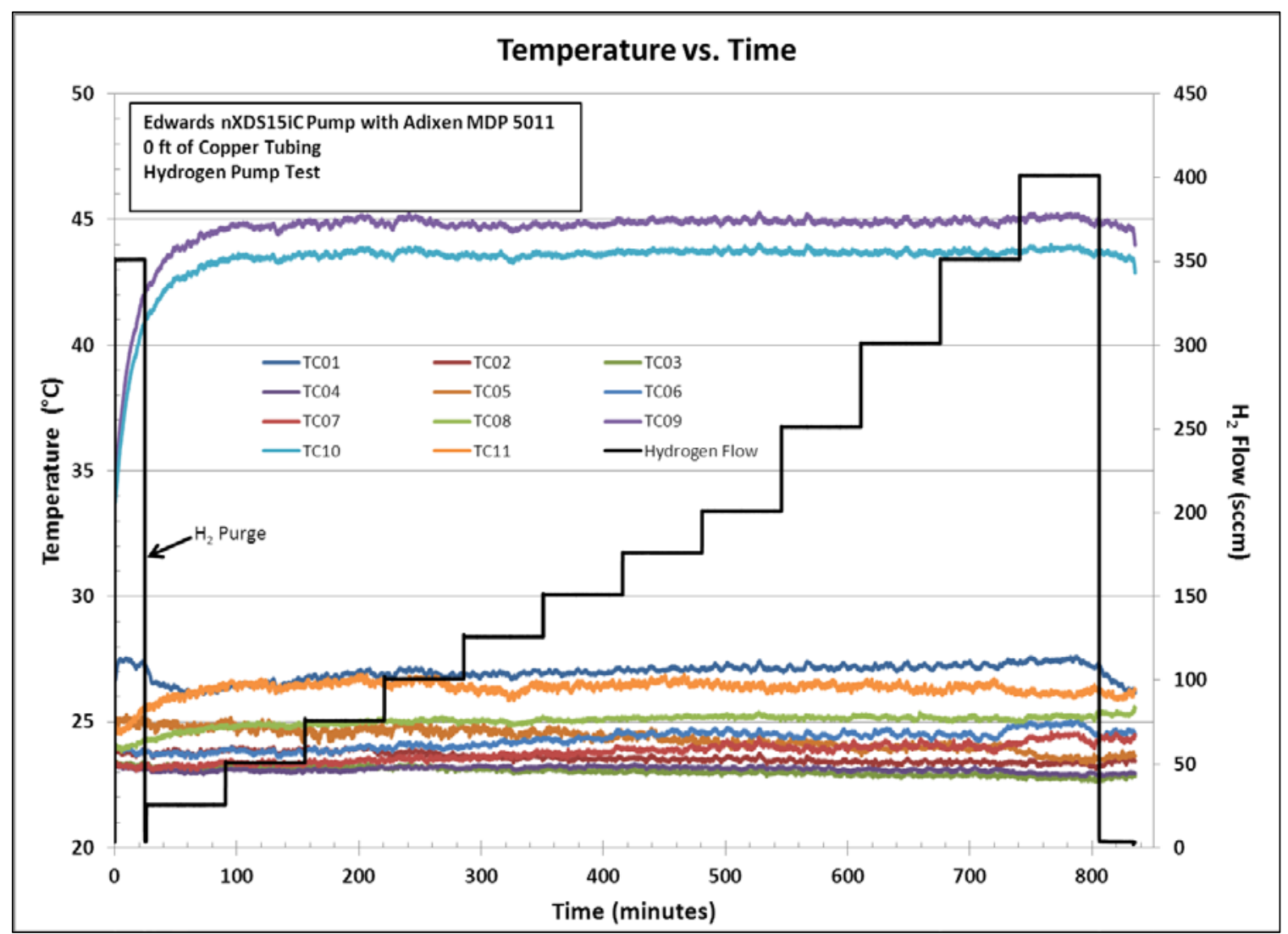

Figure 3-18: Temperature vs. Time plot for plot hydrogen with the Edwards pump, Adixen molecular drag pump, and 0 feet of tubing. 


\subsubsection{Static Pump Down Testing}

For each configuration, static pump down tests were completed using the nominal 45-L volume for both nitrogen and hydrogen. In all test cases, the 45-L volume and the associated tubing were initially loaded with the test gas. The system pressure was increased to approximately 980 torr for each test gas and allowed to equilibrate for 5 minutes before opening the valve to the Edwards pump. Figure 3-19 - Figure 3-22 show that the volume is effectively evacuated (down to several torr) in approximately 5 minutes for tubing lengths of 0 and $300 \mathrm{ft}$ for $\mathrm{H}_{2}$ and $\mathrm{N}_{2}$. However, Figure 3-19 shows a step-wise evacuation observed in several tank pump down tests instead of a continuous, exponential decrease in pressure. During the periods of constant pressure in Figure 3-19, the Edwards Pump may not adequately be evacuating the system. If this were to occur during the Dynamic Flow Testing, one would expect to see the fluctuating pressure readings that were observed. It is speculated that the initial pressure fluctuations (Figure 3-5 through Figure 3-7) and these steady regions of pressure during the evacuation of the tank are ultimately related to a characteristic of the pump and not a result of the mass flow controller. Generally when $\mathrm{N}_{2}$ was used for the pump down tests the ultimate pressure in the system was lower compared to $\mathrm{H}_{2}$. Typically following a test using hydrogen, the system was flushed with nitrogen to aid in the evacuation of residual hydrogen from the system.

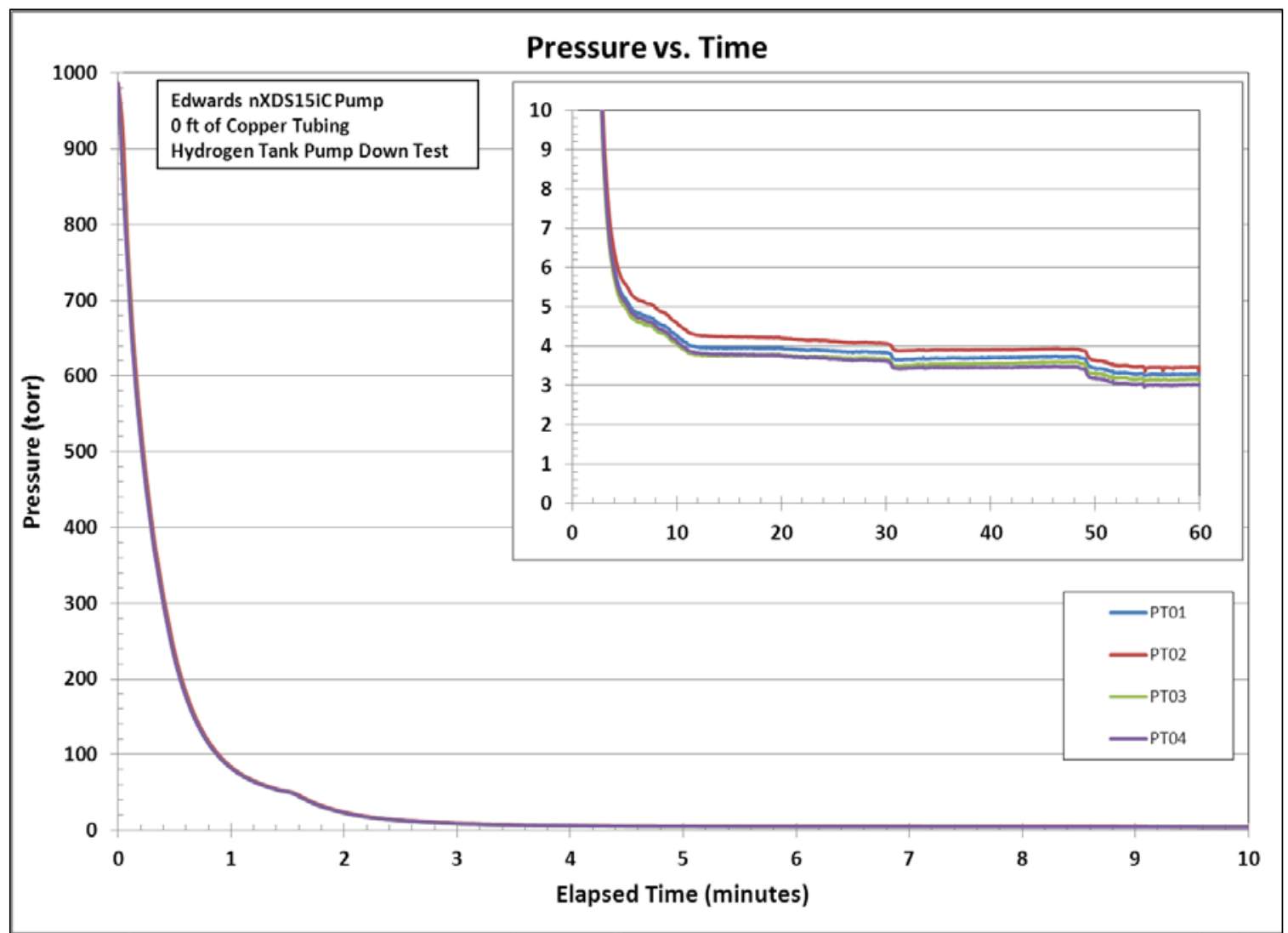

Figure 3-19: Pressure vs. Time plot for tank pump down test with hydrogen with the Edwards pump and 0 feet of tubing. 


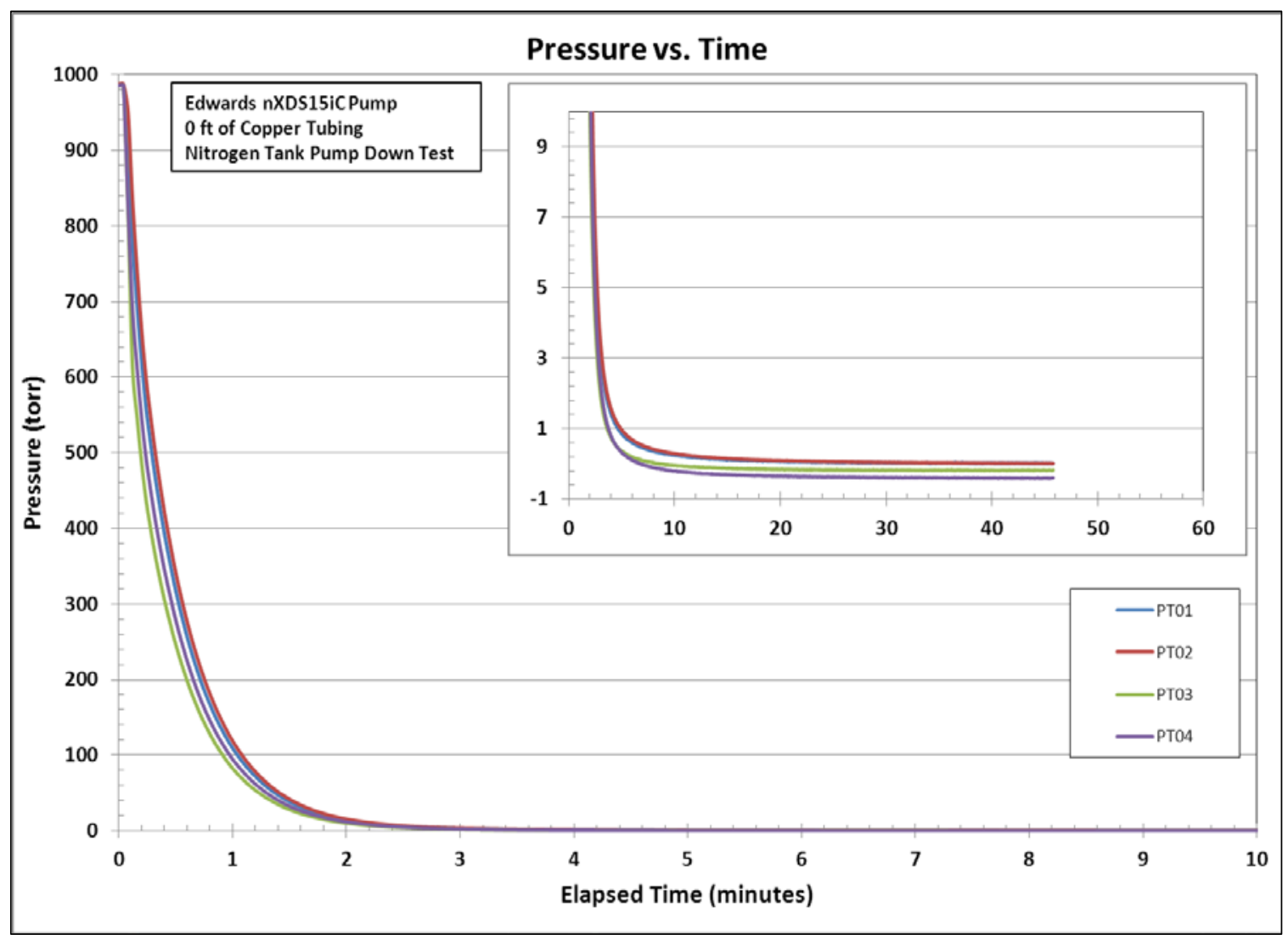

Figure 3-20: Pressure vs. Time plot for tank pump down test with nitrogen with the Edwards pump and 0 feet of tubing. 


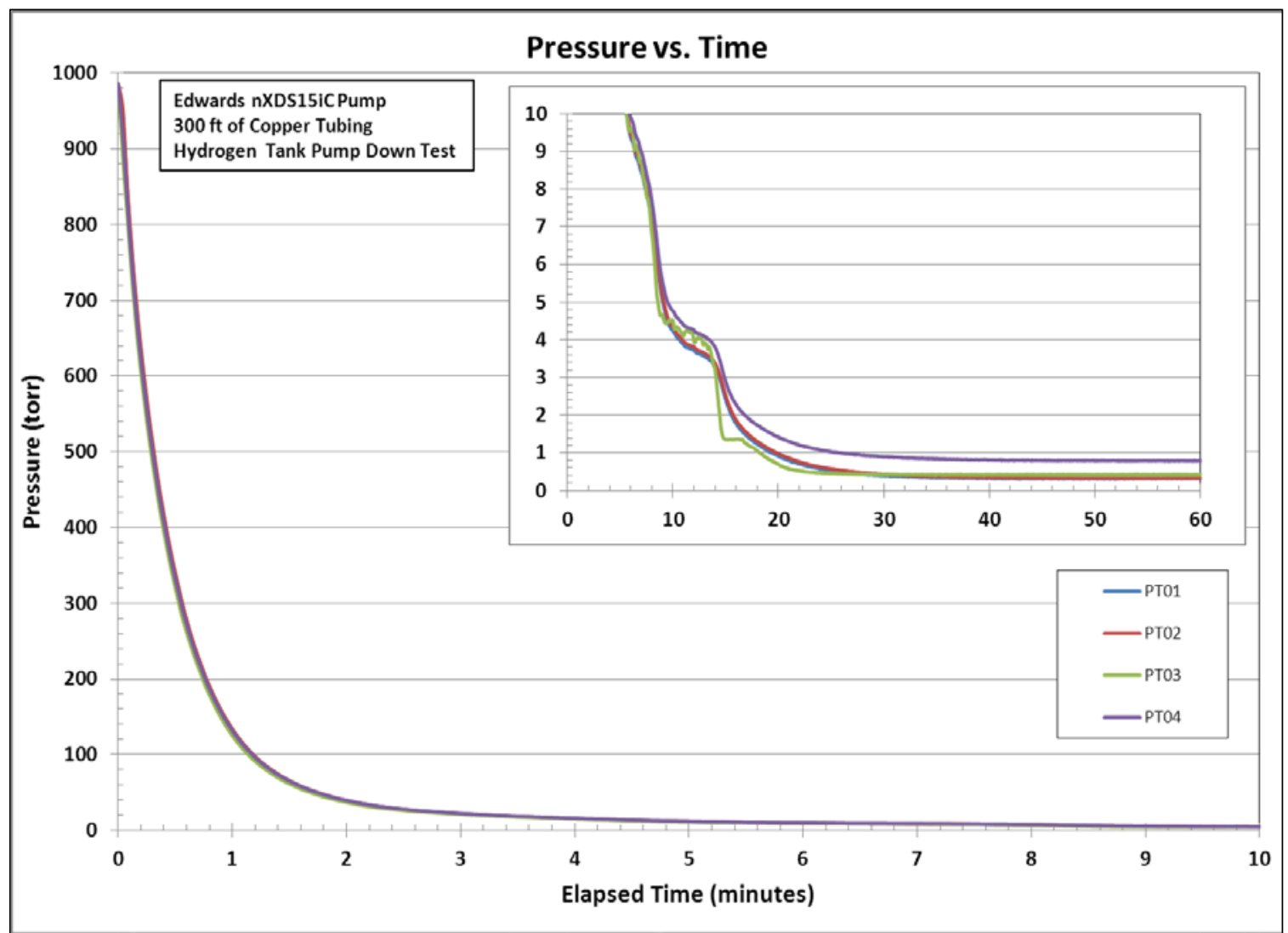

Figure 3-21: Pressure vs. Time plot for tank pump down test with hydrogen with the Edwards pump and 300 feet of tubing. 


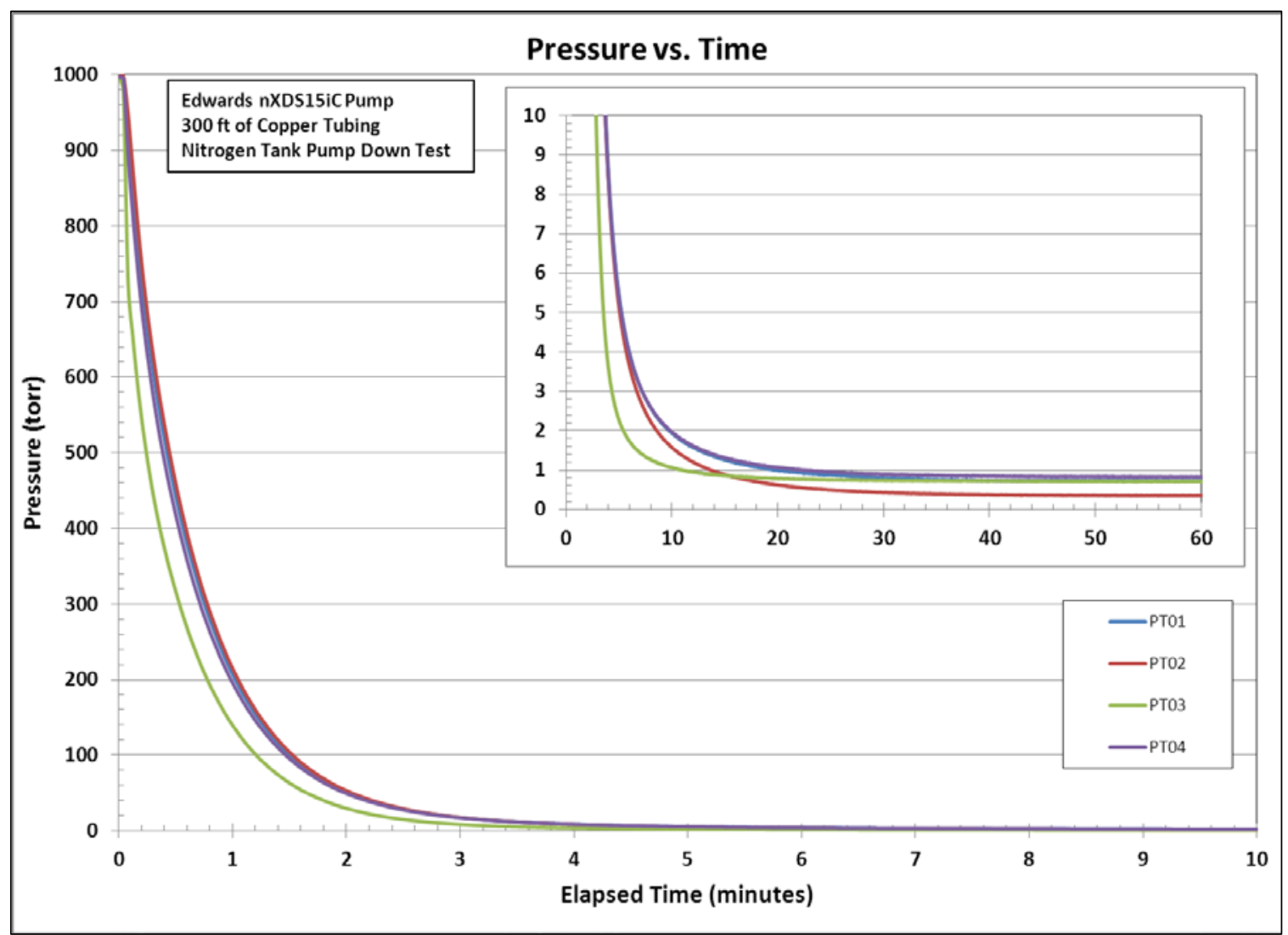

Figure 3-22: Pressure vs. Time plot for tank pump down test with nitrogen with the Edwards pump and 300 feet of tubing. 
Data gathered from the various pump down tests is plotted differently in Figure 3-23 through Figure 3-25. These figures show the direct comparison of the pump performance at each transducer location for the different test conditions. These plots show the point at which the system pressure is less than 0.5 torr, as indicated by the horizontal line in each figure and inset.

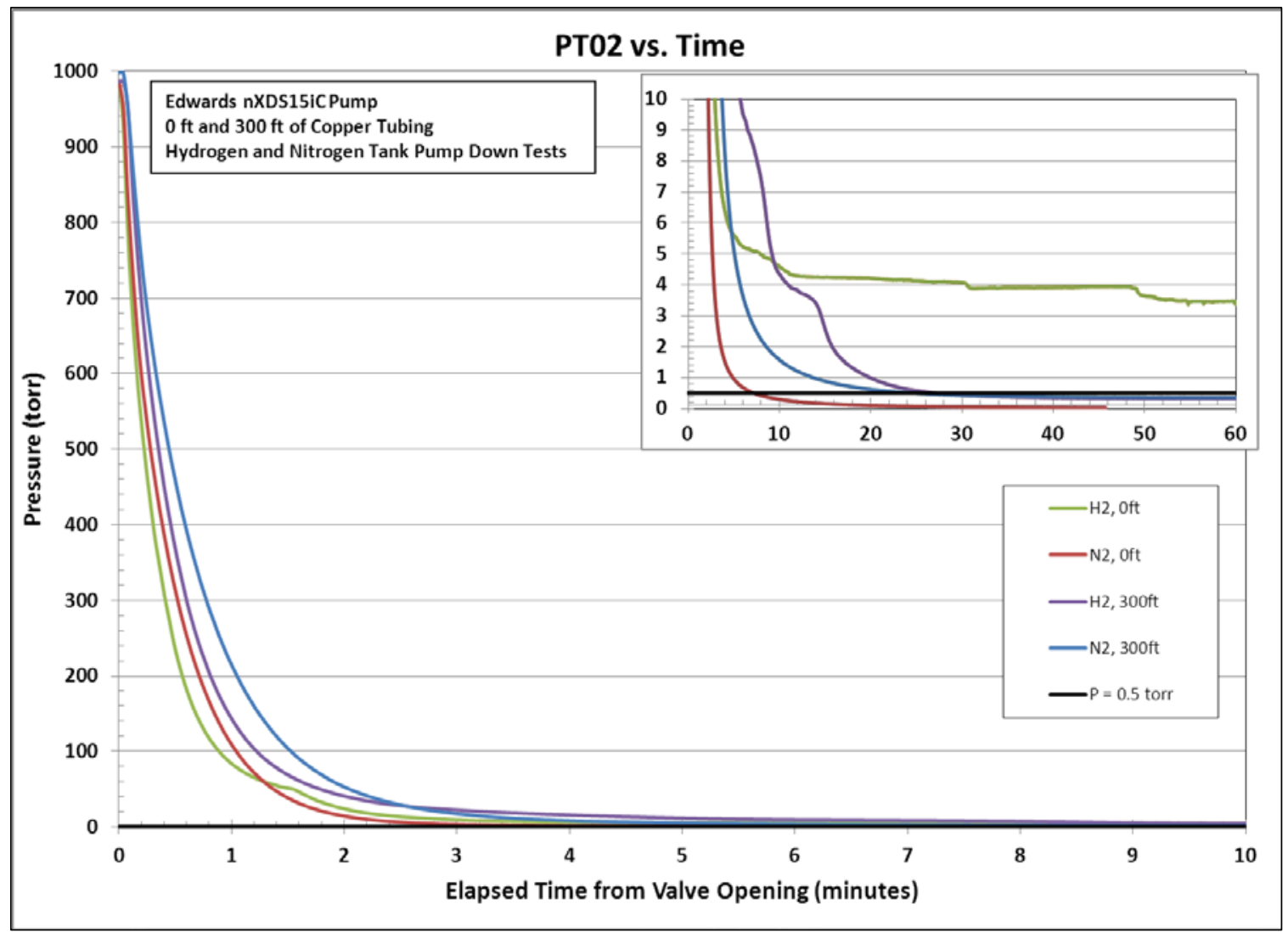

Figure 3-23: Pressure vs. Time plot for the various test conditions at PT02 


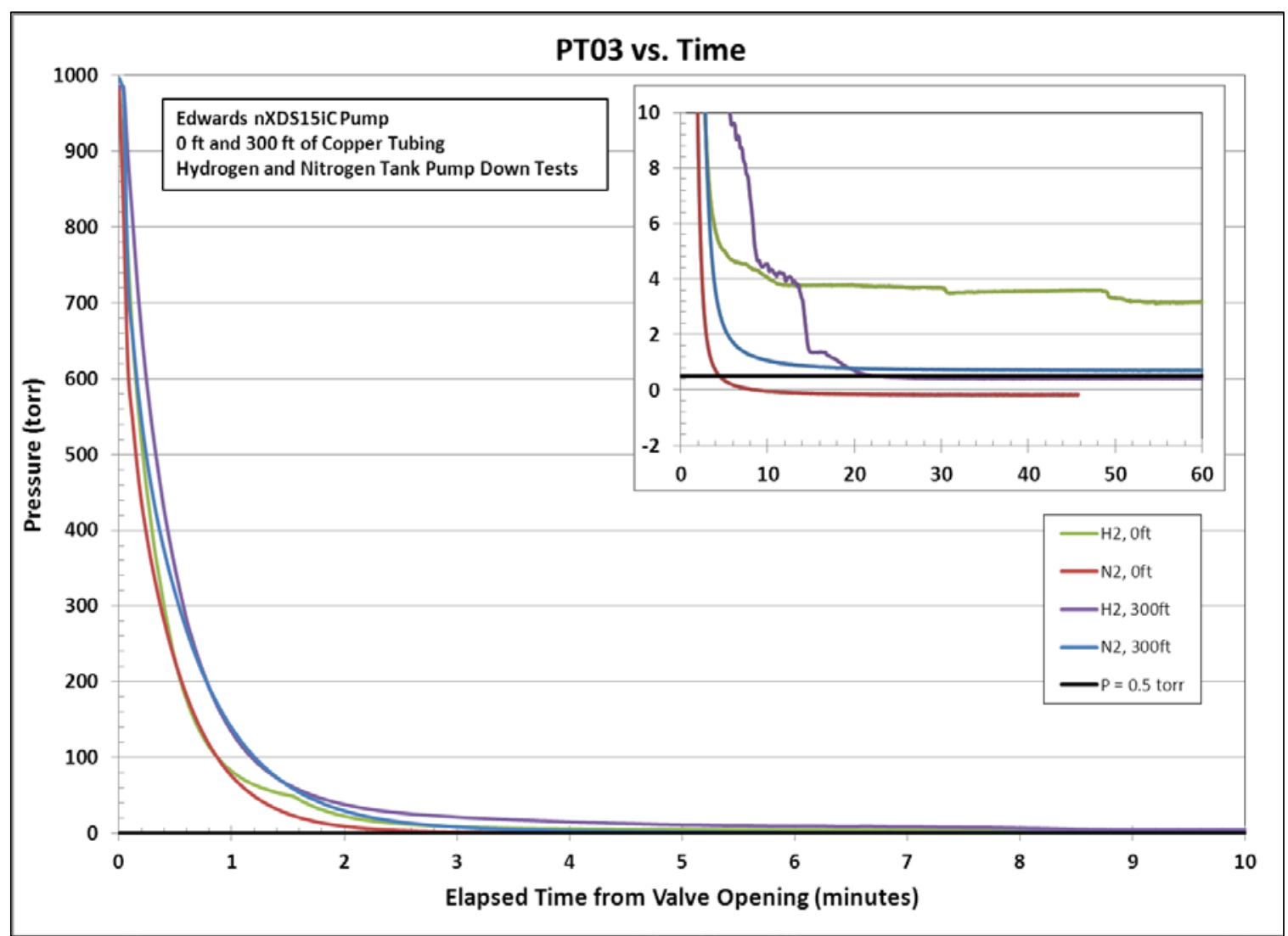

Figure 3-24: Pressure vs. Time plot for the various test conditions at PT03 


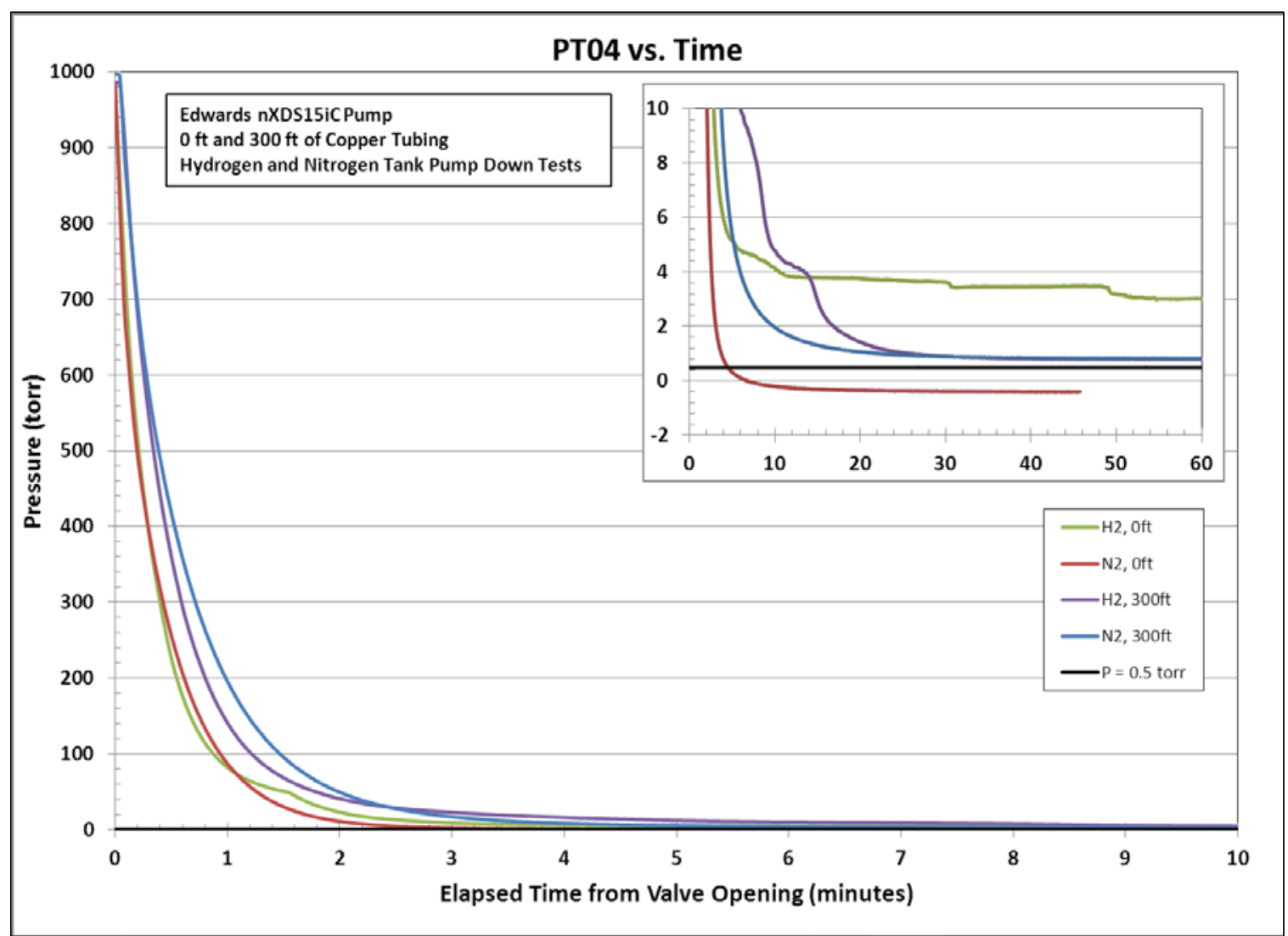

Figure 3-25: Pressure vs. Time plot for the various test conditions at PT04 


\subsection{Conclusions}

The results obtained show the Adixen 5011 MDP and Edwards nXDS15iC pump configuration as candidate pumps for the SHINE ATIS and TPS TGRS. Although for some tests, the inlet pressure of the MDP exceeded its stated maximum value of $10 \mathrm{mbar}$ (7.5 torr), the pump continued to operate - likely because the discharge pressure was lower than the 40 mbar (30 torr) discharge pressure limit and the pump was not operating beyond its capabilities. The molecular drag pump was able to maintain its operational 27K RPMs (full speed) even when the flow rate was $400 \mathrm{sccm}$ hydrogen or nitrogen with 300 feet of $\mathrm{Cu}$ tubing installed between the molecular drag pump and the Edwards scroll pump. In addition to the MDP maintaining its operating speed, the pressure in the system tubing was maintained below the desired pressure of 30 torr for all flow rates, lengths of tubing, and process gases.

The MDP has enough capacity to receive gas from all eight NDAS units for delivery to TGRS, however, it is not certain if one pump can service all eight NDAS units. Other than move gas, the MDP is to supply a low pressure on the down-stream side of a pressure control device for proper accelerator operation. A separate MDP may be required in each NDAS ATIS to supply this necessary function.

These results indicate that the Edwards nXDS15iC scroll pump is a potential replacement for the Normetex scroll pump in the SHINE TPS system provided an impurity removal process is installed on the discharge of the pump to collect particulates. For Edwards pumps exposed to tritium, an impurity removal system will be needed to process byproduct impurities of tritium exposure to pump elastomer components. The results also show the adequacy of the Edwards pump as the evacuation pumps for the PESS TPS-EVAC system based on the results obtained from the $45 \mathrm{~L}$ tank pump-down tests. 


\subsection{References}

1. Klein, James E. SHINE Tritium Purification System Pre-Conceptual Design Report. Aiken, SC : Savannah River National Laboratory, 2013. SRNL-TR-2013-00043.

2. Heroux, K.J. and A. S. Poore. SHINE Tritium Processing System: Technology Identification and Development Plan. 2013. SRNL-TR-2013-00015 Rev. 0.

3. Heroux, K.J., et al., et al. SHINE Tritium Purification System Technology Assessment Study. Aiken, SC : Savannah River National Laboratory, 2013. SRNL-TR-2013-00135.

4. SRNS. SHINE Tritium Purification System Process Flow Diagram. July 31, 2013. M-M5-W00009 Rev. 0A.

5. Clark, E.A. Normetex Pump Alternatives Study. Aiken, SC : Savannah River National Laboratory, 2013. SRNL-STI-2013-00325.

6. Klein, J.E. SHINE Tritium Process Mass Balance. 2013. SRNL-TR-2012-00279 Rev. 1. 